\title{
Effect of ageing heat treatments on the microstructure and intergranular corrosion of powder metallurgy duplex stainless steels
}

\author{
C. García, F. Martín *, Y. Blanco, M.L. Aparicio \\ Materials Engineering, E.I.I., Universidad de Valladolid. C/ Paseo del Cauce 59, 47011 Valladolid, Spain
}

\section{A R T I C L E I N F O}

\section{Article history:}

Received 13 April 2010

Accepted 19 July 2010

Available online 23 July 2010

\section{Keywords:}

A. Stainless steel

B. Polarization

C. Intergranular corrosion

C. Repassivation

\begin{abstract}
A B S T R A C T
The influence of ageing heat treatments $\left(675\right.$ and $875^{\circ} \mathrm{C}$ for 1.5 to $48 \mathrm{~h}$ ) on the microstructure and intergranular corrosion resistance of sintered in nitrogen duplex stainless steels was investigated. The materials were obtained by sintering mixtures of austenitic AISI 316L and ferritic AISI 430L powders. Corrosion behaviour was evaluated by using electrochemical techniques. The beneficial effect of nitrogen on corrosion behaviour of solution annealed samples was established. During ageing, secondary phases were precipitated and the intergranular and transgranular corrosion resistance significantly decreased though repassivation was observed in specimens aged at $875{ }^{\circ} \mathrm{C}$ for times up to $8 \mathrm{~h}$.
\end{abstract}

(c) 2010 Elsevier Ltd. All rights reserved.

\section{Introduction}

Sintered duplex stainless steels (DSS) are the newest materials in the SS family that seem to be very promising in some applications like automobile components. Usually wrought duplex SS are characterized by a two-phase structure with approximately equal amounts of ferrite and austenite. Powder metallurgy (PM) technology offers an ability to produce a broader spectrum of alloy compositions with unique properties. However, the inherently residual open porosity and the problems arising from industrial sintering atmospheres [1,2] limit their corrosion resistance.

The corrosion behaviour of wrought duplex SS is strongly dependent on the microstructure, namely the presence of sigma phase, carbide and nitride precipitates [3-9]. For PM duplex SS the chromium depletion process due to precipitation of secondary phases acts synergistically with interconnected pores and consequently lower corrosion resistance is achieved [1,2,10,11].

Corrosion behaviour of PM duplex SS obtained through mixed ferritic and austenitic powders has been studied by immersion test, $[12,13]$ in the salt fog spray test $[11]$ and preliminary electrochemical testing [1,2,12-14]. Generally speaking, PM duplex SS obtained from mixing, show lower corrosion resistance but better pitting corrosion resistance than wrought duplex SS [12].

Duplex SS sintered in vacuum or in hydrogen are investigated in many works $[2,11,13,15-18]$ but little information is found about PM duplex SS sintered in nitrogen. The optimization of wrought

\footnotetext{
* Corresponding author. Tel.: +34 983423515; fax: +34 983184514

E-mail address: fmp@eis.uva.es (F. Martín).
}

and cast duplex SS has resulted in continuous material development related to their alloying, especially with nitrogen and the resulting mechanical, corrosion and wear properties as well as weldability [19-22]. PM is one of the more interesting methods for intentionally raised nitrogen content. Sintering in nitrogen is potentially valuable because nitrogen is directly incorporated into the material. The positive effect of $\mathrm{Cr}$, Mo and $\mathrm{N}$ on PREN number (Pitting Resistance Equivalent Number) is known but only if they are in solid solution and homogeneously distributed $[23,24]$. If precipitated, nitrogen plays a negative role [10,21,24-29].

Prior works about localized corrosion on PM SS sintered in nitrogen atmosphere indicated that these materials could not be used in the as-sintered state due to their poor corrosion behaviour. Their intergranular corrosion and pitting resistance results lead to the conclusion that solution annealing shows a beneficial effect on corrosion resistance. Annealed samples sintered in nitrogen show better corrosion behaviour than those sintered in vacuum [14,25-27].

Electrochemical reactivation methods can successfully detect the degree of sensitization (DOS) in PM duplex SS by measuring the reactivation associated to chromium depleted areas of the lamellar constituent [14]. The diffusion of $\mathrm{Cr}$ and Mo from austenite into ferrite gives similar corrosion resistance for the two phases, therefore hindering corrosion initiation [17].

Once it is established that the best corrosion resistance properties of PM duplex SS are for sintered in nitrogen and subsequently solution annealed materials, it is interesting to investigate their intergranular corrosion (IGC) resistance after ageing at sensitization temperatures. 
There are some works about the influence of ageing heat treatments for conventional duplex and superduplex SS [4,7,9,30,31] and about the relevance of nitrogen on the corrosion behaviour of sensitized materials $[5,26,32]$, but there is no information about this issue for PM duplex SS. A recent work has proved that there are microstructural changes after isothermal-ageing treatments of PM duplex SS that promotes hardness increase but the influence on corrosion behaviour was not investigated [33].

One of the issues of this work is to investigate a broad selection of temperatures-times sensitization conditions. Additionally, the effects of heat treatments in PM duplex SS have been analyzed and compared for different compositions and sintered atmospheres. Sensitization heat treatment temperatures, where the formation of secondary phases takes place, were intentionally chosen in order to induce the precipitation of several and different precipitates. High temperatures and long times of sensitization have been also applied to try to heal the materials.

\section{Experimental}

\subsection{Materials}

Two prealloyed and water atomized powders were used in this work: AISI 430L (0.018 wt.\% C, 1.16 wt.\% Si, 0.18 wt.\% Mn, 16.9 wt.\% Cr, 0.10 wt.\% Ni, Fe bal.) and AISI 316L (0.021 wt.\% C, 0.87 wt.\% Si, 0.20 wt.\% Mn, 16.1 wt.\% Cr, 13.55 wt.\% Ni, 2.24 wt.\% Mo, 0.02 wt.\% Cu, Fe bal.). Powder characteristics of AISI 430L were: apparent density $3.0 \mathrm{~g} / \mathrm{cm}^{3}$, flow rate $26 \mathrm{~s} / 50 \mathrm{~g}$ and nominal particle size $<150 \mu \mathrm{m}$. Powder characteristics of AISI 316L were: apparent density $3.1 \mathrm{~g} / \mathrm{cm}^{3}$, flow rate $25 \mathrm{~s} / 50 \mathrm{~g}$ and nominal particle size $<150 \mu \mathrm{m}$.

Premixes of $316 \mathrm{~L}$ and $430 \mathrm{~L}$ were prepared in a turbular mixer. The content of AISI $316 \mathrm{~L}$ was set to $25,50,65,75$ or 85 wt.\%. Disc specimens (25 $\mathrm{mm}$ diameter and $6 \mathrm{~mm}$ height) were uniaxially compacted using a floating die at $750 \mathrm{MPa}$. Zinc stearate was used as die lubricant. Green compacts were sintered in $\mathrm{N}_{2}-\mathrm{H}_{2}$ (95\% and $5 \%$ ) at $1250{ }^{\circ} \mathrm{C}$ for $30 \mathrm{~min}$ and at a cooling rate of $5{ }^{\circ} \mathrm{C} / \mathrm{min}$. The materials were designated as $25 \mathrm{~N}, 50 \mathrm{~N}, 65 \mathrm{~N}, 75 \mathrm{~N}$ and $85 \mathrm{~N}$, respectively and named "as-sintered specimens". For comparative purposes, some samples were sintered in vacuum at $1250{ }^{\circ} \mathrm{C}$ for $30 \mathrm{~min}$ (designated herein as $50 \mathrm{~V}$ ). A number of sintered samples were solution annealed at $1150{ }^{\circ} \mathrm{C}$ for 60 min under a stream of argon before being water quenched. These were referred to as the "annealed specimens". For detecting the DOS some of these annealed specimens were then subjected to sensitization or ageing heat treatment by heating at temperatures of $675^{\circ} \mathrm{C}$ or $875^{\circ} \mathrm{C}$ under a stream of argon for $90 \mathrm{~min}, 4,8$ or $48 \mathrm{~h}$ and then air cooled. All of these samples were referred to as "aged specimens".
Table 2

Porosity obtained by image analysis of the base materials (316L and 430L) and duplex SS sintered in nitrogen and in vacuum; as-sintered and after annealing solution treatment.

\begin{tabular}{llc}
\hline Samples & Porosity (\%) \\
\cline { 2 - 3 } & Sintered & Annealed \\
\hline 430L N & 17.99 & 13.22 \\
316L N & 13.61 & 11.96 \\
$25 \mathrm{~N}$ & 13.87 & 11.88 \\
$50 \mathrm{~N}$ & 12.87 & 11.78 \\
$65 \mathrm{~N}$ & 23.50 & 14.37 \\
$75 \mathrm{~N}$ & 11.55 & 8.77 \\
$85 \mathrm{~N}$ & 14.13 & 12.22 \\
$430 \mathrm{~L} \mathrm{~V}$ & 15.52 & 12.89 \\
$316 \mathrm{~L} \mathrm{~V}$ & 12.92 & 10.68 \\
$50 \mathrm{~V}$ & 12.71 & 9.54 \\
\hline
\end{tabular}

Additionally, discs of base materials AISI 430L and AISI 316L were compacted, sintered and heat treated under the same conditions (designated herein as 430L $\mathrm{N}$ and $316 \mathrm{~L} \mathrm{~N}$ for samples sintered in nitrogen and 430L V and 316L V for those sintered in vacuum).

Densities of greens, sintered compacts and annealed samples were calculated from the mass and physical dimension measurements. Porosity was determined by image analysis. Tables 1 and 2 .

Samples were polished and etched before observation by optical metallography and SEM/EDS (scanning electron microscopy with energy dispersive analysis of X-rays). X-ray diffraction (XRD) was conducted to help in identifying some phases. Additionally, some bulk extracted powders were analyzed by XRD. Bulk extraction was performed by electrolytic dissolution of the matrix with $10 \%$ $\mathrm{HCl}$ in methanol solution at 5-6 V. Residues were filtered and XRD was performed for identifying precipitated secondary phases.

\subsection{Corrosion resistance evaluation tests}

\subsubsection{ASTM A262, Practice A}

ASTM A262, Practice A [34], was used for microstructural characterization of the specimens in their different treatment states (as-sintered, annealed and sensitized). Electrochemical etching with oxalic acid helped to define both the rate and the location of chromium precipitates. The quality of the material was then classified according to the three basic categories: step, dual and ditch.

\subsubsection{Electrochemical Potentio-Kinetic Reactivation Test (EPR)}

The test was performed following ASTM standard G-108 [35]. The test conditions and evaluation criterion used were similar to conventional stainless steels case and only small modifications have been applied. Nevertheless, since the results have been

Table 1

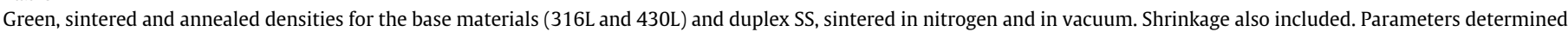
by ASTM B328-96 oil impregnation method and standard deviation of \pm 0.05 .

\begin{tabular}{|c|c|c|c|c|c|c|}
\hline \multirow[t]{2}{*}{ Samples } & \multicolumn{4}{|c|}{ Densities $\left(\mathrm{g} / \mathrm{cm}^{3}\right)$} & \multicolumn{2}{|c|}{ Shrinkage (\%) } \\
\hline & Green & Sintered & $\begin{array}{l}\text { Relative density }{ }^{\mathrm{a}} \\
(\%)\end{array}$ & Annealed & Sintered & Annealed \\
\hline 430L N & 6.38 & 6.72 & 87.3 & 6.90 & 5.06 & 2.61 \\
\hline 316L N & 6.60 & 6.77 & 85.7 & 6.89 & 2.51 & 1.74 \\
\hline $25 N$ & 6.39 & 6.80 & 88.3 & 6.95 & 6.02 & 1.83 \\
\hline $50 N$ & 6.40 & 6.90 & 88.5 & 7.00 & 7.25 & 1.43 \\
\hline $65 \mathrm{~N}$ & 6.50 & 6.55 & 83.7 & 7.10 & 0.76 & 7.75 \\
\hline $75 N$ & 6.60 & 6.62 & 84.6 & 7.10 & 0.58 & 6.44 \\
\hline $85 N$ & 6.70 & 6.73 & 85.6 & 7.10 & 0.45 & 5.21 \\
\hline 430L V & 6.38 & 6.79 & 88.2 & - & 6.04 & - \\
\hline $316 \mathrm{~L} \mathrm{~V}$ & 6.60 & 6.82 & 86.3 & - & 3.23 & - \\
\hline $50 \mathrm{~V}$ & 6.38 & 7.01 & 89.9 & - & 8.99 & - \\
\hline
\end{tabular}

\footnotetext{
${ }^{\text {a }}$ Relative density $=$ sintered density with respect to theoretical density (theoretical densities of $430 \mathrm{~L}=7.7 \mathrm{~g} / \mathrm{cm}^{3}$ and $316 \mathrm{~L}=7.9 \mathrm{~g} / \mathrm{cm}^{3}$ ).
} 
shown to be dependent on the type of surface preparation of the sample, prior electrolytic conditioning [36] was carried out. The EPR conditions are described in the ASTM standard. The electrolyte was $0.5 \mathrm{M} \mathrm{H}_{2} \mathrm{SO}_{4}+0.01 \mathrm{M} \mathrm{KCN}$ and the test temperature $30^{\circ} \mathrm{C} \pm 1$. A Saturated Calomel Electrode (SCE) was used as reference electrode. The experimental parameters of the conditioning were the following: a delay of $5 \mathrm{~min}$ at open circuit potential $\left(\mathrm{V}_{\mathrm{OC}}\right)$, deaerated, an anodic attack at $-220 \mathrm{mV}_{\mathrm{SCE}}$, a delay of $2 \mathrm{~min} \mathrm{~V}_{\mathrm{OC}}$, a cathodic cleaning at $-600 \mathrm{mV}_{\mathrm{SCE}}$ for $1 \mathrm{~min}$ and a delay of $5 \mathrm{~min}$ at $\mathrm{V}_{\mathrm{OC}}$. Passivation was accomplished by applying $+200 \mathrm{mV}_{\mathrm{SCE}}$ for $2 \mathrm{~min}$. The reactivation scan started at $200 \mathrm{mV}_{\mathrm{SCE}}$ until $50 \mathrm{mV}_{\mathrm{SCE}}$ below the $\mathrm{V}_{\mathrm{OC}}$ at a rate of $100 \mathrm{mV} / \mathrm{min}$. Nitrogen sparging and agitation were used throughout the whole test. The EPR testing parameters, $Q_{r}$ (reactivation charge) and $I_{\mathrm{r}}$ (reactivation current density) were used to evaluate the DOS.

\subsubsection{Double Loop Electrochemical Potentio-Kinetic Reactivation Test (DLEPR)}

The test was carried out following the test conditions proposed elsewhere [37,38]. The surface preparation of the sample was finished with a $1 \mu \mathrm{m}$ diamond polish; the electrolyte was $0.5 \mathrm{M}$ $\mathrm{H}_{2} \mathrm{SO}_{4}+0.01 \mathrm{M} \mathrm{KCN}$ and the test temperature $30{ }^{\circ} \mathrm{C} \pm 1$.

There were three stages in the test: $5 \mathrm{~min}$. delay at $\mathrm{V}_{\mathrm{OC}}$, to determine corrosion potential; anodic polarization scan from $E_{\text {corr }}$ (corrosion potential) to a potential of $300 \mathrm{mV}_{\mathrm{SCE}}$, in the passive range at a scanning rate of $100 \mathrm{mV} / \mathrm{min}$; cathodic reactivation scan from $300 \mathrm{mV}_{\mathrm{SCE}}$ to $E_{\mathrm{Corr}}$. The results of the test, expressed as the ratio of the current densities, $I_{\mathrm{r}} / I_{\mathrm{a}}$, and the charges, $Q_{\mathrm{r}} / Q_{\mathrm{a}}$, given in percentages, were used to evaluate susceptibility to IGC or degree of sensitization. $I_{\mathrm{r}}$ and $Q_{\mathrm{r}}$ are the maximum reactivation current density and charge during reverse scan and $I_{\mathrm{a}}$ and $Q_{\mathrm{a}}$ are the maximum passivation current density and charge during anodic scan.

A conventional corrosion cell with three electrodes was used. The testing specimen was used as the working electrode, two graphite rods as counter -electrodes and a SCE equipped with a Luggin capillary as the reference electrode. The area of the working electrode was about $0.5 \mathrm{~cm}^{2}$ (the complete section of the plate). For deaeration purposes, nitrogen bubbling and stirring from $30 \mathrm{~min}$ before starting the test until its completion was used.

\section{Results and discussion}

\subsection{ASTM A262, Practice A and microstructural characterization}

The role of nitrogen on corrosion resistance is related to the chromium depletion associated with the precipitation of secondary phases. Therefore it is necessary to undertake a microstructural study using ASTM A262, Practice A, not only in terms of a qualitative estimate of the DOS but also as a microstructural characterization for as-sintered, annealed and sensitized specimens.

\subsubsection{As-sintered and annealed states}

The microstructural characterization of the PM base materials and duplex stainless steels sintered in nitrogen for as-sintered and annealed states have been mostly studied by the authors in previous works $[14,39]$. The main characteristics are hereafter outlined.

For 430L N, a lamellar constituent formed by lamellae of chromium precipitates and an interlamellar matrix of chromium depleted ferrite and/or $\alpha^{\prime}$-martensite was observed. Intensive intergranular precipitation was also found. Both, lamellar and coarse intergranular precipitates were identified as chromium nitrides/carbonitrides but SEM/EDS analysis confirmed slight differences of chemical composition. For 316L N, a lamellar constituent similar in shape to the former was observed. The lamellar constitu- ent was formed by chromium precipitates in a matrix of austenite and was in lower proportion and with smaller interlamellar spacing than for the 430L N. The austenite grains showed a ditch structure on boundary grain and deep pits associated to transgranular precipitates. The precipitates were identified as complex nitride/carbides.

The metallographic study of PM duplex SS sintered in nitrogen $[14,39]$ revealed, for every composition of mixture, the presence of coarse and fine lamellar constituents plus a non-lamellar constituent with IG and isolated TG precipitates. The amount of coarse lamellar constituent was the highest for $25 \mathrm{~N}$ and decreased sequentially from $25 \mathrm{~N}$ to $85 \mathrm{~N}$, whereas the relative content of the fine lamellar constituent was progressively increasing. The overall amount of both lamellar constituents decreased from $25 \mathrm{~N}$ to $85 \mathrm{~N}$ and increased the amount of non-lamellar constituent. For this last one, SEM/EDS study indicated that it was heterogeneous with a chemical composition intermediate between austenite and ferrite, so it was called mixed constituent. When the austenite/ferrite ratio increased, besides the intergranular ditch of mixed constituent, deep pits appeared inside and were smaller and more globular than those associated to lamellar constituents.

Annealing promoted total dissolution of the lamellar constituents and the IG and TG precipitates. Dissolution of the lamellar constituents was found for annealed PM duplex SS but still complex microstructures were observed: grains of austenite free of precipitates and a darker and heterogeneous constituent with platelet-like substructure. The SEM/EDS study confirmed that it was formed by ternary ferrite-austenite-martensite phases, i.e., mixed constituent and presented a chemical composition intermediate between the typical austenite and ferrite powders. The amount of this mixed constituent decreased when the ratio of austenite/ferrite on mixture, increased.

The base and duplex stainless steels sintered in vacuum showed a simpler microstructure and similar to conventional SS: austenite for $316 \mathrm{~L}$, ferrite for $430 \mathrm{~L}$ and austenite with ferrite islands for duplex SS. However, after annealing, duplex SS revealed the presence of some mixed constituent with an appearance similar to samples sintered in nitrogen.

\subsubsection{Ageing heat treatments}

The effect of the ageing for PM duplex SS has not been described so far. Hereafter, a detailed description will be given. The sensitization behaviour must be highly dependant on temperature/time ageing heat treatment as well as on the type of sintering atmosphere. Precipitation of carbon and nitrogen rich phases (intermetallic precipitates) will also be a function of these parameters.

For the case of base materials sintered in nitrogen, sensitization at the critical $675{ }^{\circ} \mathrm{C}$ temperature showed for $316 \mathrm{~L} \mathrm{~N}$ samples [28] slight TG carbide precipitation. With increasing heat treatment time, a progressive intergranular etching was detected showing ditch structure type for the longer heat treatments. At higher temperature $\left(875^{\circ} \mathrm{C}\right)$, a lower IG attack than at $675^{\circ} \mathrm{C}$ was observed but on the contrary, a strong increase of TG etching was noticed. The $430 \mathrm{~L} \mathrm{~N}$ specimens aged at $675{ }^{\circ} \mathrm{C}$ [29] for the shorter ageing times showed strong IG and sparse TG etching. For longer times, massive precipitation inside ferrite grains was observed and, for much longer heat treatment $(48 \mathrm{~h})$, precipitates with lamellar morphology similar in shape to as-sintered specimens were found. Ferritic specimens aged at $875^{\circ} \mathrm{C}$ resulted, for the shortest time, in the formation of extensive TG precipitation and for $48 \mathrm{~h}$, the entire ferrite grains were transformed into lamellar precipitate with a high level of decomposition into globular and coarse precipitates.

The ageing heat treatment at $675^{\circ} \mathrm{C}$ resulted in a strong dissolution on PM duplex SS even for the shorter times, especially for samples with lower relation of austenite/ferrite, i.e. $25 \mathrm{~N}$ and $50 \mathrm{~N}$. In general, for the shortest times, some dissolution of the mixed 
constituent, continuous dissolution of the austenite in grain boundary and ditch structure were observed. For $8 \mathrm{~h}$ of ageing, the amount of the dissolved mixed constituent was strongly increasing although some small areas remain untransformed. For $48 \mathrm{~h}$ of ageing, the dissolution of the mixed constituent was continuing and a strong TG attack in the austenite was observed. This etching showed preferential orientation in some of the grains. In Fig. 1 are collected the micrographs for 50N showing its microstructural evolution.

For the whole set of aged specimens some differences were seen related to the change in relative amounts of austenite and ferrite. Increasing the relative amount of austenite/ferrite promoted the decreasing of the amount of transformed mixed constituent and became more evident in the precipitation in the austenitic phase. For the shortest times ( 1.5 to $4 \mathrm{~h}$ ) the attack was intergranular while for 8 and especially 48 h the attack was mainly transgranular. Furthermore, for $48 \mathrm{~h}$, the precipitation was discontinuous and in some areas, the structure was cellular and similar to that seen in as-sintered specimens. The microstructural evolution during isothermal ageing for $75 \mathrm{~N}$ is shown in Fig 2.

Ageing for $48 \mathrm{~h}$ was obviously the treatment promoting the stronger microstructural changes, however it was not clearly observed due to the strong attack of the oxalic etching. Consequently, a Vilella's reagent was also used throughout the study to observe with detail the evolution of the mixed constituent. In Fig. 3 are collected a set of micrographs for $25 \mathrm{~N}$ aged at different time intervals and etched by Vilella's reagent. The SEM/EDS study, Fig. 4, allows concluding that when ageing for $48 \mathrm{~h}$, the mixed constituent transforms into a lamellar constituent formed by complex carbide-nitrides of chromium and iron in a chromium depleted $(14 \% \mathrm{Cr})$ and low $\mathrm{Ni}(1.5 \%)$ matrix.
Base materials sintered in vacuum that aged at $675^{\circ} \mathrm{C}$ showed a much lower IG and TG globular precipitation and no lamellar precipitates. In addition, the precipitation sequence was similar to those observed in specimens sintered in nitrogen, i.e., started with IG precipitation after short times and, from $8 \mathrm{~h}$ and more, TG precipitates appeared. In addition, the microstructural evolution of aged duplex SS sintered in vacuum was similar to samples sintered in nitrogen. The shorter heat treatment dissolved the mixed constituent but for $8 \mathrm{~h}$ of ageing, some untransformed areas were still detected. The etching of austenitic phase was less especially the TG type. Samples with the longest ageing time showed homogeneity of the microstructure but the main etching in austenite phase was intergranular and no lamellar constituent was observed as for samples sintered in nitrogen.

The ageing at $875^{\circ} \mathrm{C}$, for duplex SS sintered in nitrogen, promoted a stronger dissolution than at $675^{\circ} \mathrm{C}$, especially for the shorter sensitization times. The $25 \mathrm{~N}$ sample already showed a nearly total dissolution for $1.5 \mathrm{~h}$, Fig. $5 \mathrm{a}$. When the austenite/ferrite ratio increased, the general etching was less intensive and the evolution of the mixed constituent and the austenite phase separately were observed. The transformed mixed areas appeared delimited by coarse needles and with lamellar precipitates inside. The austenite phase showed ditch structure in the grain boundary and intensive TG precipitation. As observed in Fig. 5b-e the amount of this constituent increased with the sequence $50 \mathrm{~N}, 65 \mathrm{~N}, 75 \mathrm{~N}$, and $85 \mathrm{~N}$.

Longer ageing $\left(875^{\circ} \mathrm{C}\right)$ resulted in a more homogeneous microstructure for every sample. Both the mixed constituent areas and the austenite phase evolved into a matrix with intense precipitation inside, Fig. 6a. At higher magnification, two types of mechanisms of precipitation can be identified: one associated with the
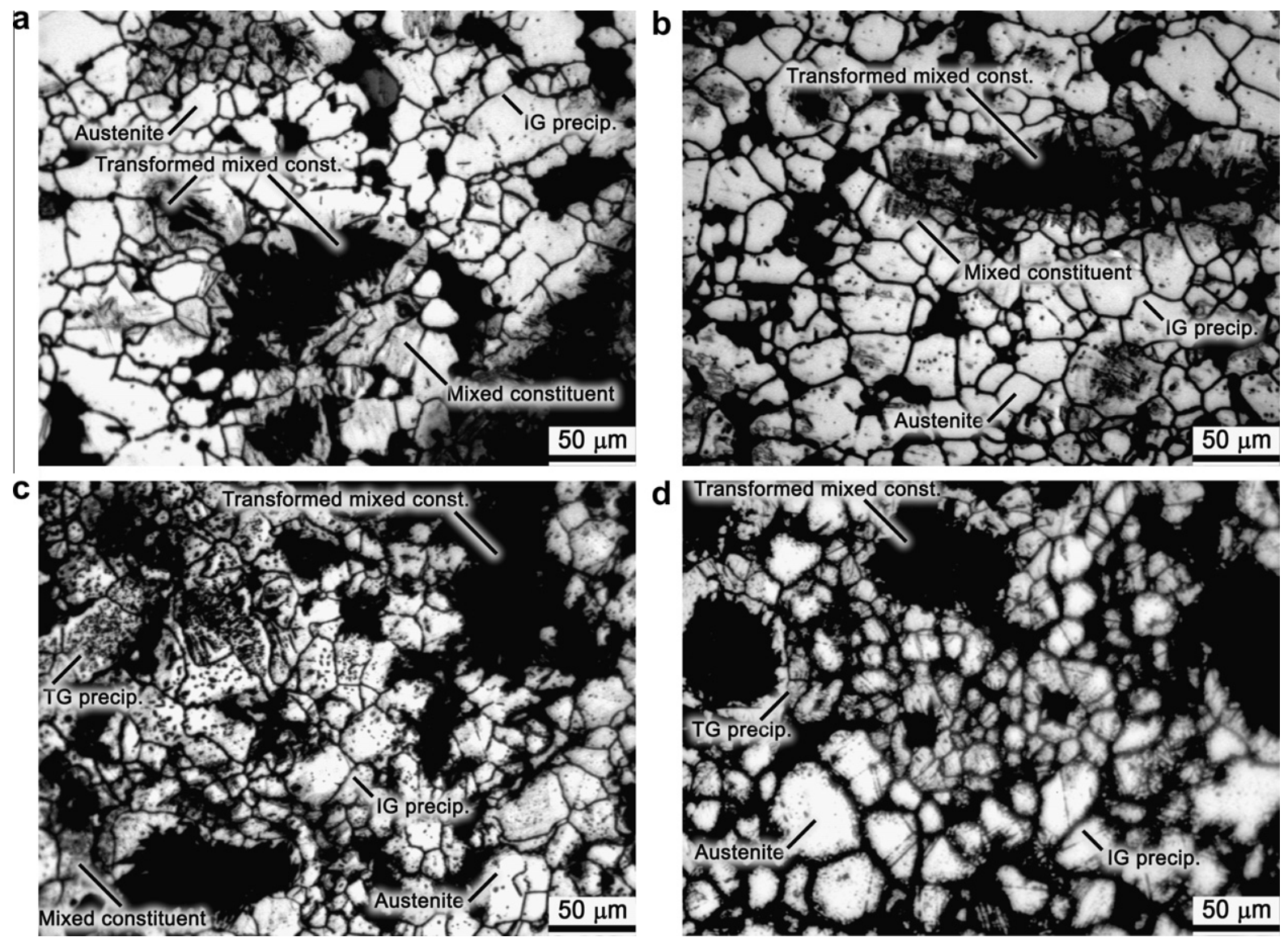

Fig. 1. Microstructures after Practice A (ASTM A262) of $50 \mathrm{~N}$ sensitized at $675{ }^{\circ} \mathrm{C}$ for (a) 1.5 , (b) 4 , (c) 8 and (d) $48 \mathrm{~h}$. 

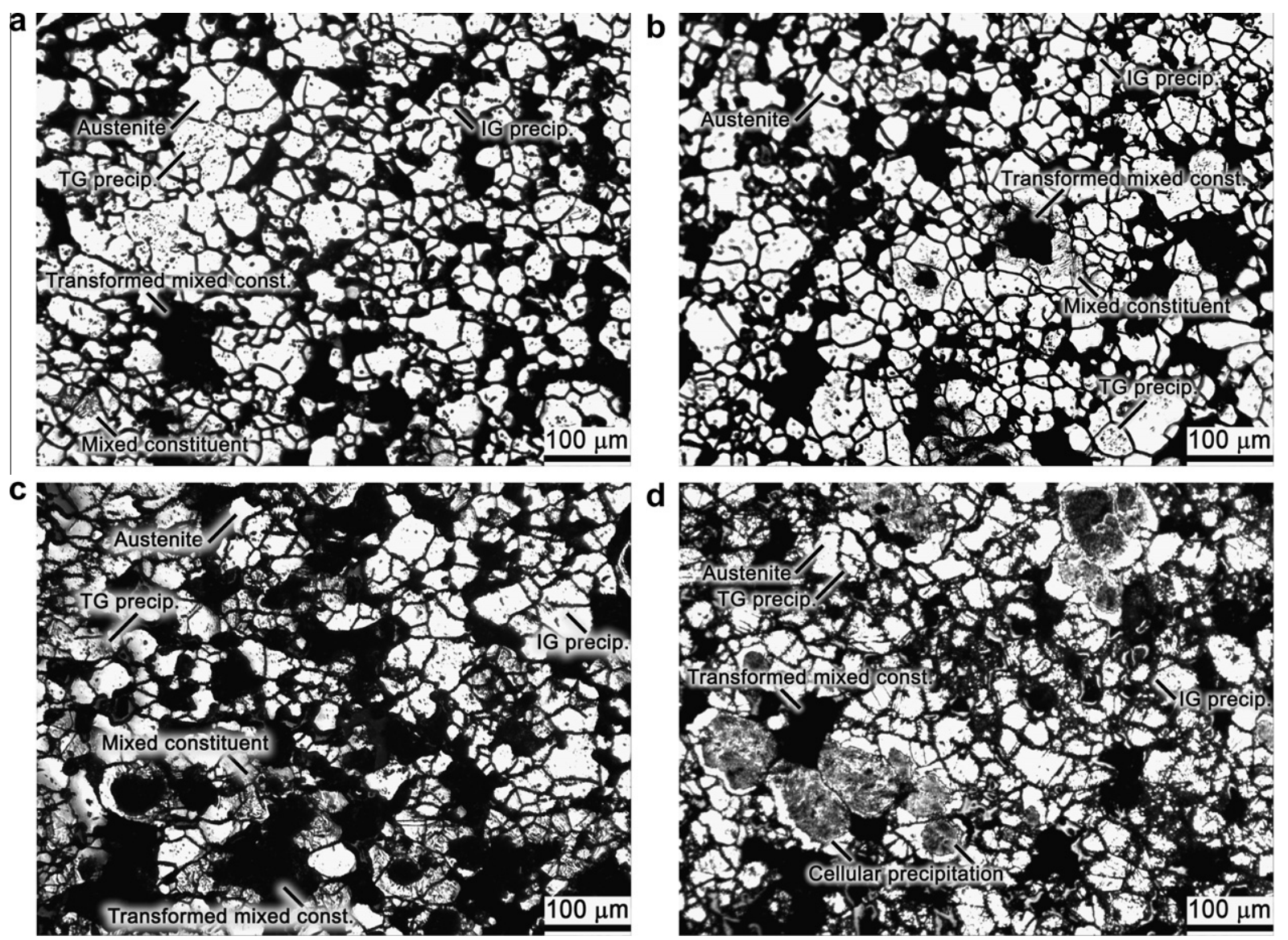

Fig. 2. Microstructures after Practice A (ASTM A262) of $75 \mathrm{~N}$ sensitized at $675{ }^{\circ} \mathrm{C}$ for (a) 1.5 , (b) 4 , (c) 8 and (d) $48 \mathrm{~h}$.

typical precipitation of lamellar precipitates, which is a continuous precipitation mechanism, and the other related with precipitates oriented to the crystallographic planes and associated to discontinuous precipitation, Fig. $6 \mathrm{~b}$ and $\mathrm{c}$.

Vilella's reagent once again was used to distinguish between the darker areas, corresponding to transformed mixed constituent, and the lighter areas, of aged austenite with IG precipitates, Fig. 7a. In the darker areas, a continuous precipitation was the main TG precipitation mechanism while discontinuous precipitation occurred in the austenite phase, Fig. 7b. The SEM/EDS study confirmed this point, Fig. 8 showing three types of precipitates: intergranular, lamellar transgranular and oriented transgranular. The EDS analysis indicated that the interlamellar matrix had a lower percentage of $\mathrm{Ni}$ and Mo than the matrix with oriented discontinuous precipitates. In both cases chromium depletion in the matrices was effectively observed.

XRD studies indicated that longer ageing at $875^{\circ} \mathrm{C}$ originated destabilization of the gamma phase and increase of alpha phase content, Fig 9a. Regarding chromium precipitates, it can be concluded that there were more carbides (mainly $\mathrm{M}_{7} \mathrm{C}_{3}$ type) and carbonitrides than $\mathrm{M}_{2} \mathrm{~N}$ nitrides $(\mathrm{M}=\mathrm{Cr}, \mathrm{Fe}$ ). In Fig 9b, diffractograms corresponding to bulk extracted powders are shown. Some iron and chromium oxides arising from the long term exposure to high temperature were also present.

Ageing at high temperature originated an intensive precipitation on vacuum treated samples. The evolution of the precipitation process with sensitization time was similar to that seen on nitrogen samples. For shorter heat treatments, besides dissolution of transformed mixed constituent and intergranular precipitation on austenite phase, isolated transgranular precipitation was observed on ferrite islands, Fig. 10a. For low and intermediate sensitization times, also two types of precipitation mechanisms could be found: cellular precipitation and discontinuous precipitation, Fig. 10b. For longer sensitization also certain homogeneity was detected, the main constituent appeared with continuous intergranular precipitates and with an intensive transgranular precipitation, Fig. 10c. However, some mixed constituent areas were still present with lamellar precipitates of the same kind as those observed for shorter sensitization times, Fig. 10d.

\subsection{Electrochemical Potentio-Kinetic Reactivation Test (EPR)}

EPR can successfully detect the DOS in PM duplex SS sintered in nitrogen by measuring the reactivation associated with chromium depleted areas [14]. Previous works [14,28,29] indicate that $Q_{r}$ parameter is recommended to be used instead of $I_{\mathrm{r}}$ since the former is an integration value while the latter is just a point value. Additionally, due to the porosity, the real current density cannot be correctly estimated.

For base and duplex materials sintered in nitrogen, high DOS values were detected for as-sintered condition. This behaviour is associated with chromium depleted areas of the lamellar constituent. The amount of lamellar constituents is the main factor contributing to corrosion behaviour, when it increases the corrosion also increases. EPR results indicated that $316 \mathrm{~L} \mathrm{~N}$ was the one with the best behaviour followed by duplex SS and 430L N. Focusing on the influence of the austenite/ferrite ratio, it was observed that DOS decreases as the ratio increases.

By comparing as-sintered specimens sintered in vacuum and in nitrogen it was seen that the reactivation data were clearly lower for the former. However, porosity was similar and therefore, porosity was not the main influencing factor. It should be considered 

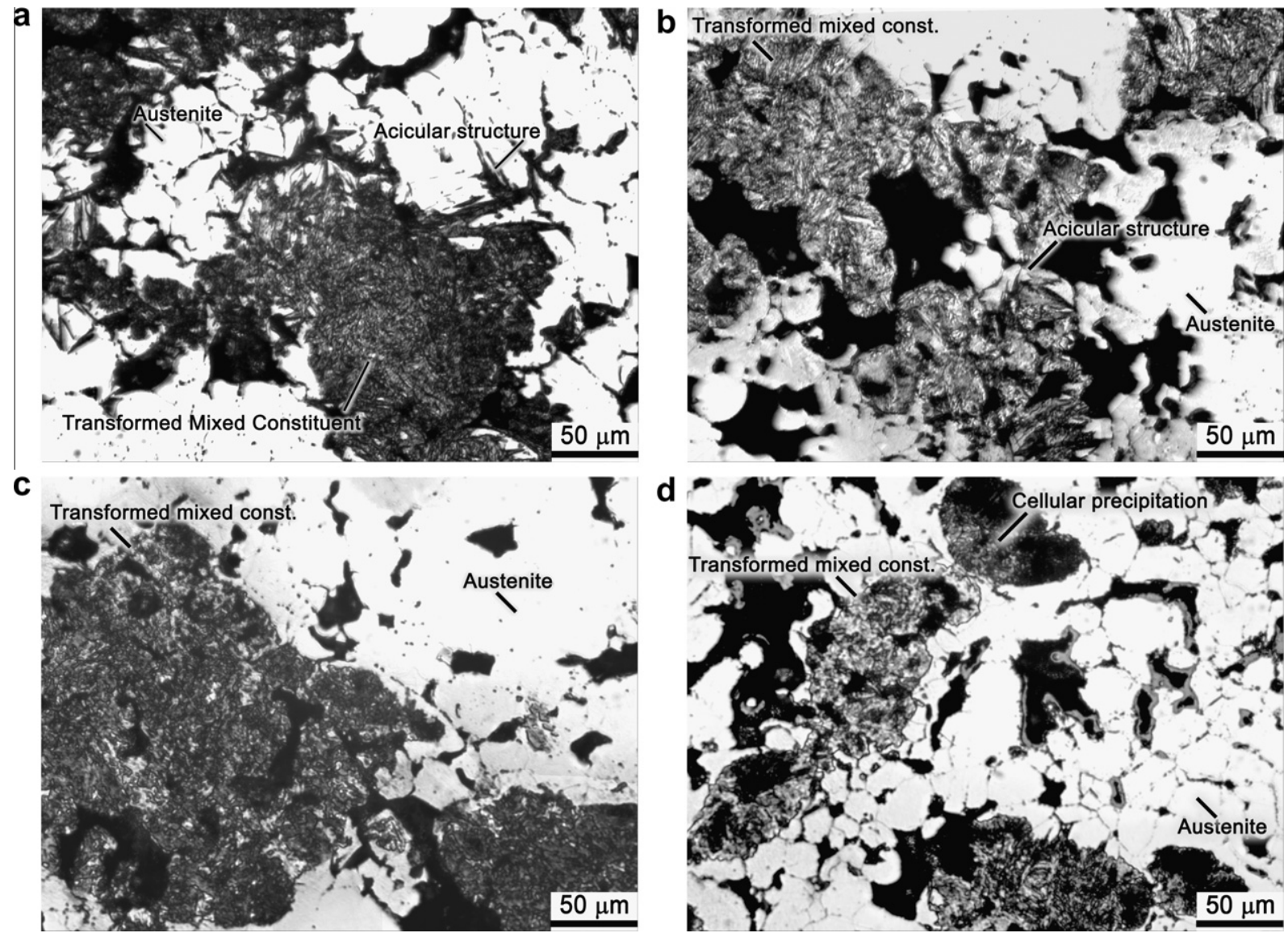

Fig. 3. Microstructures after Vilella's reagent of $25 \mathrm{~N}$ sensitized at $675{ }^{\circ} \mathrm{C}$ for (a) 1.5 , (b) 4 , (c) 8 and (d) $48 \mathrm{~h}$.

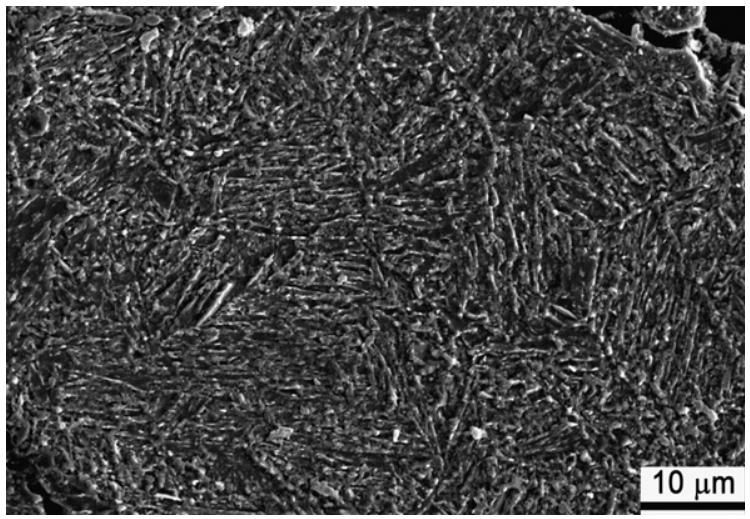

Fig. 4. SEM micrograph of $25 \mathrm{~N}$ sensitized at $675{ }^{\circ} \mathrm{C}$ for $48 \mathrm{~h}$.

that the chromium depleted areas found nearby the nitrogen rich precipitates are responsible. Therefore, duplex stainless steels sintered in nitrogen cannot be used in the as-sintered state due to their poor corrosion behaviour. It was necessary to use a solution annealing heat treatment. As expected, annealing was effective for the dissolution of the lamellar constituents and a significant increase in corrosion resistance was observed. It seems that this was due to the re-diffusion of chromium into the previous depleted areas. This effect is so important that the annealed samples sintered in nitrogen have similar or even better corrosion behaviour than those sintered in vacuum. Because nitrogen is more soluble in austenite than in ferrite, the beneficial effect of nitrogen was more evident when the amount of austenite powders increased.
Subsequent ageing $\left(675\right.$ and $\left.875^{\circ} \mathrm{C}\right)$ also caused some different effects in specimens with different chemical composition and different sintering atmosphere. Some pertinent issues will be hereafter outlined with emphasis on the temperature and time ageing variables.

As expected, after sensitization of base materials and duplex SS sintered in nitrogen, higher DOS was observed than for annealed specimens. The EPR data registered in Tables 3 and 4 show the sensitization behaviour for the three types of SS. Ferritic and austenitic SS showed clear differences while duplex SS showed intermediate behaviour.

The $675^{\circ} \mathrm{C}$ temperature was the typical critical sensitization temperature for austenitic stainless steels [28]. For 316L N also high DOS was registered with a clear increase of EPR data with sensitization time but it was noticed that the precipitation and subsequent sensitization occurred faster when the sensitization temperature was increased up to $875^{\circ} \mathrm{C}$, differing with what is expected for wrought stainless steels. These results could be explained in terms of a faster diffusion and decreasing saturation of nitrogen when increasing sensitization temperature promotes intense transgranular precipitation.

The typical critical temperature for sensitization of ferritic SS is $875^{\circ} \mathrm{C}$. However, for ferritic PM SS, the specimens aged at $675^{\circ} \mathrm{C}$ showed that the precipitation and subsequent sensitization occurred even faster than ageing at $875^{\circ} \mathrm{C}$. With respect to the effect of sensitization time, for $4 \mathrm{~h}$ or less, the DOS showed very small changes (slight decrease of $Q_{\mathrm{r}}$ and increase of $I_{\mathrm{r}}$ ). For more than $4 \mathrm{~h}$, the DOS rapidly increased and was coincident with the occurrence of TG precipitates. The corresponding chromium depletion caused an even higher reactivation than for as-sintered specimen. For $875^{\circ} \mathrm{C}, Q_{\mathrm{r}}$ and $I_{\mathrm{r}}$ increased with time of treatment 
a

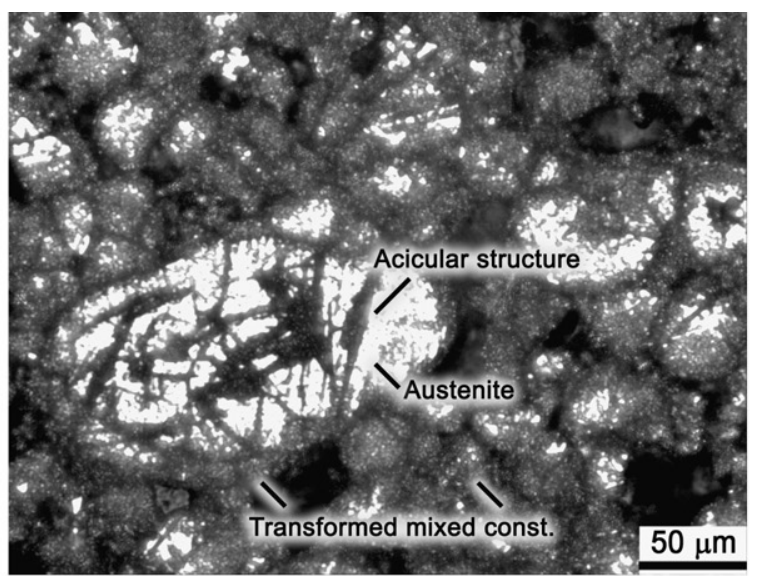

C

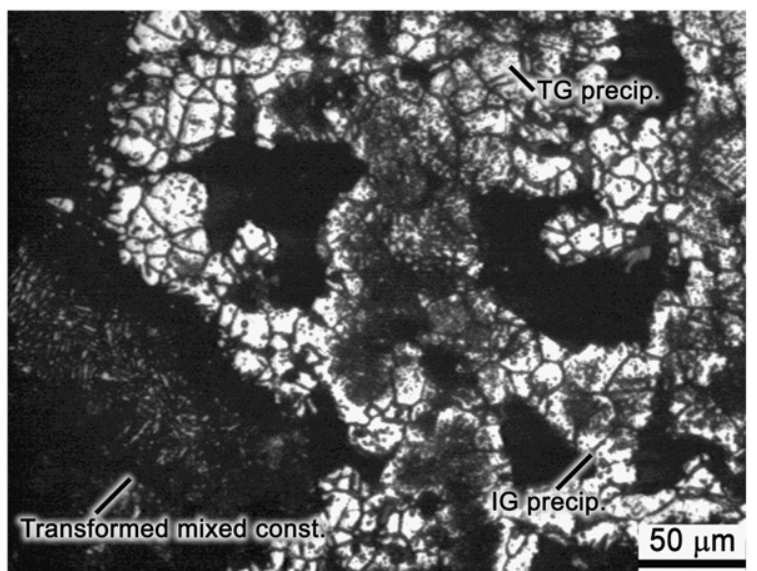

b

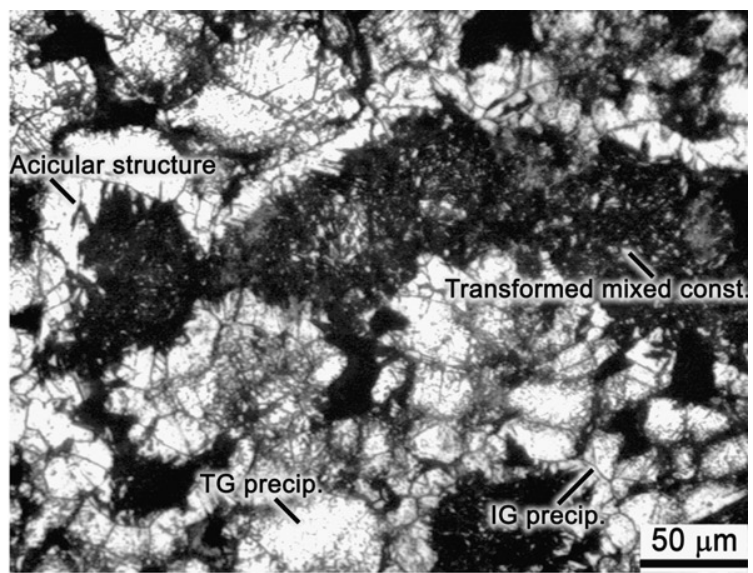

d

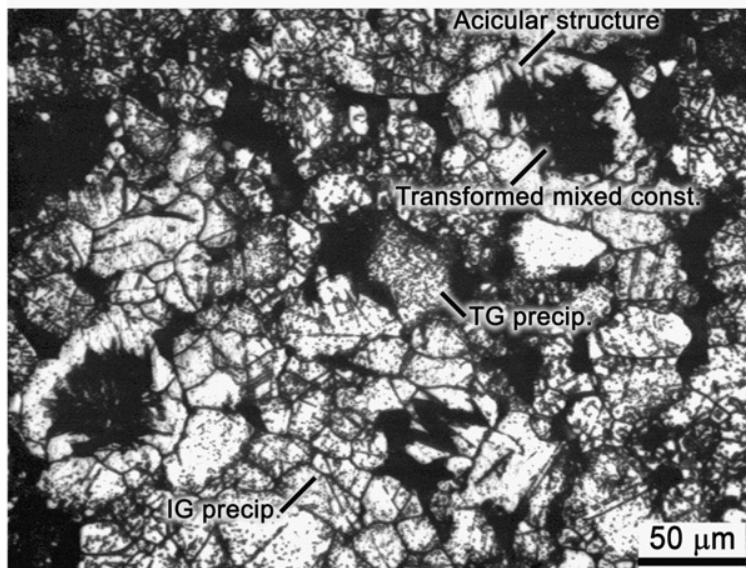

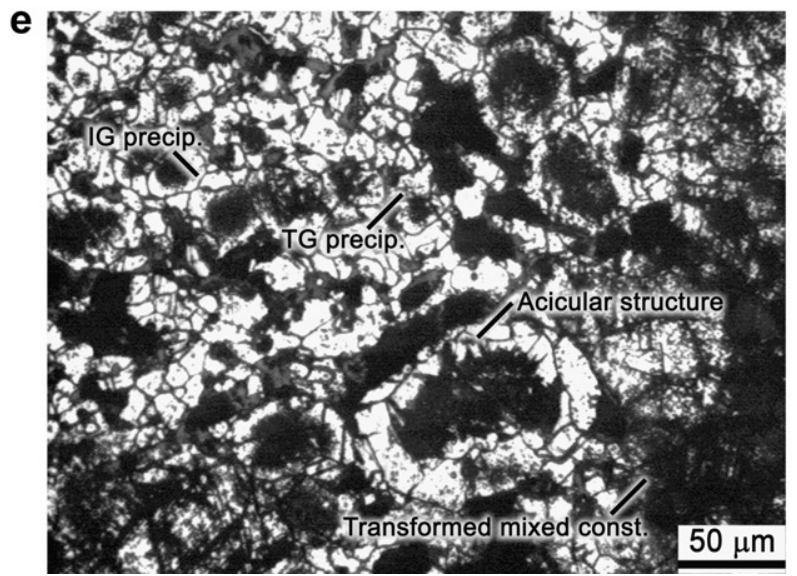

Fig. 5. Microstructures after Practice A (ASTM A262) of (a) $25 \mathrm{~N}$, (b) $50 \mathrm{~N}$, (c) $65 \mathrm{~N}$, (d) $75 \mathrm{~N}$ and (e) $85 \mathrm{~N}$, sensitized at $875^{\circ} \mathrm{C}$ for $1.5 \mathrm{~h}$

although for longer heat treatment repassivation was observed [29].

It can be observed in Tables 3 and 4 that the composition has a strong influence on DOS for duplex SS. In general, for all ageing conditions the reactivation data decreased with increasing amount of austenite powder. For both temperatures, the samples $25 \mathrm{~N}, 50 \mathrm{~N}$ and $65 \mathrm{~N}$ and $75 \mathrm{~N}$ showed a similar evolution with sensitization time while $85 \mathrm{~N}$ had a different behaviour similar to austenitic base materials.

For sensitization at $675^{\circ} \mathrm{C}$, the samples $25 \mathrm{~N}, 50 \mathrm{~N}$ and $65 \mathrm{~N}$ showed maximum DOS for the shortest and longest treatment, while for $85 \mathrm{~N}$ a continuous DOS growth with sensitization time was observed. The $75 \mathrm{~N}$ specimen showed an intermediate behaviour. For shorter ageing, the dissolution of transformed mixed con- stituent observed after the test can justify this behaviour. Therefore, the sample $25 \mathrm{~N}$ that showed the highest amount of this constituent showed a maximum reactivation, Fig. 11 . For $4 \mathrm{~h}$, the reduction of reactivation data did not correspond to the increase of etching observed, primarily on boundary grain of austenite. This could be due to a rapid repassivation of the mixed constituent. For $85 \mathrm{~N}$ with minimum amount of transformed mixed constituent this repassivation cannot be appreciated, by contrary the charge and current density were doubled.

For longer ageing, the reactivation parameters increased for every duplex composition, in accordance with the increase of transgranular etching in austenitic grains. The good behaviour of $85 \mathrm{~N}$ was noticeable for the longest sensitization time, even better than for 316L N, Fig. 12. 


\section{a}

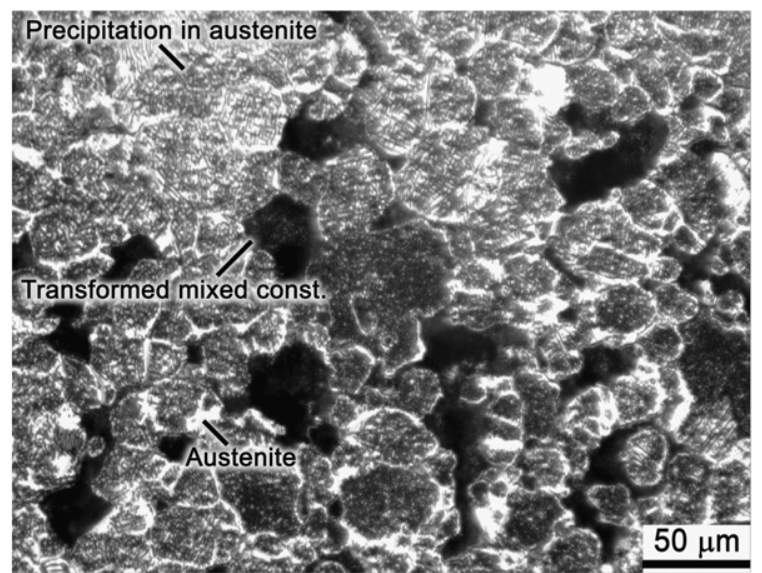

b

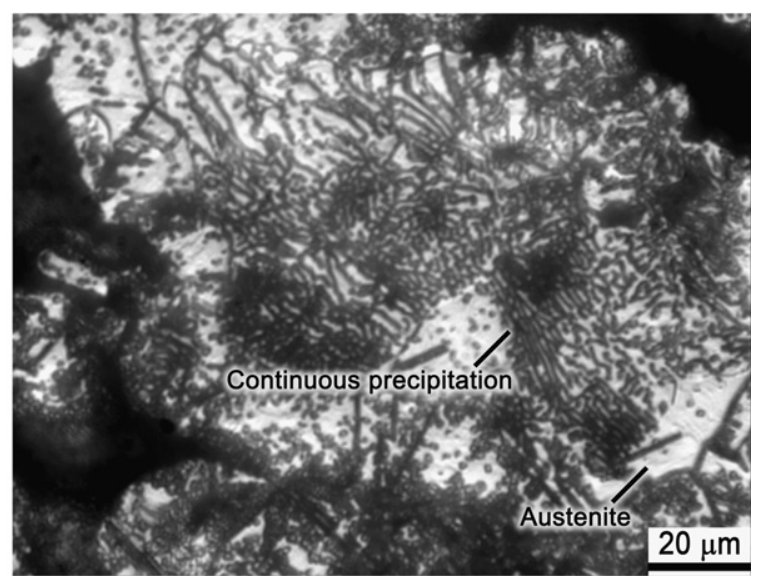

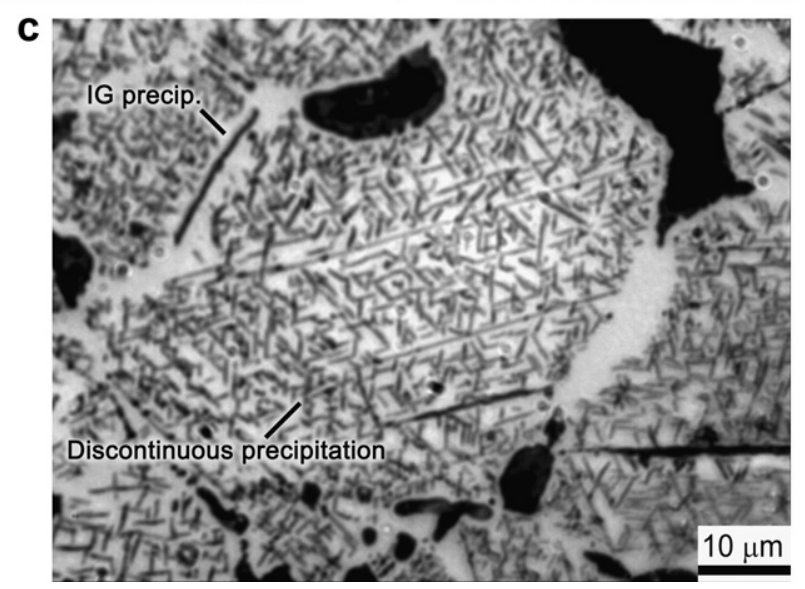

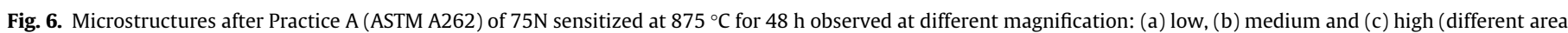
presented for each magnification).
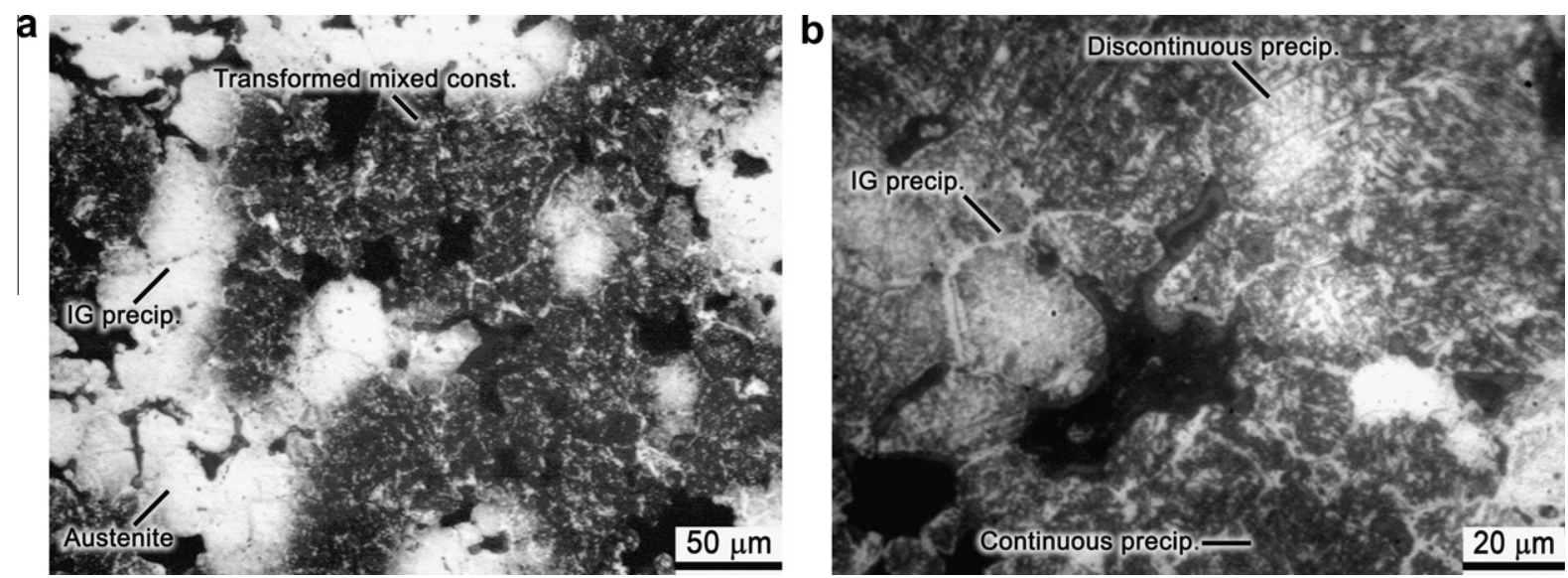

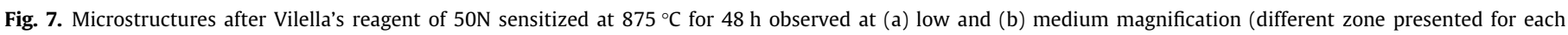
magnification).

For ageing at $875^{\circ} \mathrm{C}$ the sensitization at just $1.5 \mathrm{~h}$ was even faster than at $675^{\circ} \mathrm{C}$ and an important increase of reactivation parameters for all mixtures were observed. It was especially significant for the $85 \mathrm{~N}$ sample, Fig. 13 . The surface after testing showed an intense intergranular etching in the austenite grains and the dissolution of the mixed constituent. Transgranular etching into austenite grain was also observed. Ageing at $4 \mathrm{~h}$ produced a repassivation effect like that observed for the ferritic base material. For longer sensitization times a further increase of charge and current density were observed and this was associ- ated with the further intense lamellar and oriented precipitates observed in the austenite grains. Once again there is improved corrosion resistance of $85 \mathrm{~N}$ duplex SS for $48 \mathrm{~h}$, even better than for the austenitic base material, Fig. 14.

For sensitized specimens sintered in vacuum, Table 5 , the deleterious effect of the sensitization was remarkable for the three types of SS. The effect of sensitization for austenitic SS was similar to that of specimens sintered in nitrogen. At $675^{\circ} \mathrm{C}$, the samples sintered in nitrogen showed higher DOS values than those sintered in vacuum, showing the beneficial influence of nitrogen 


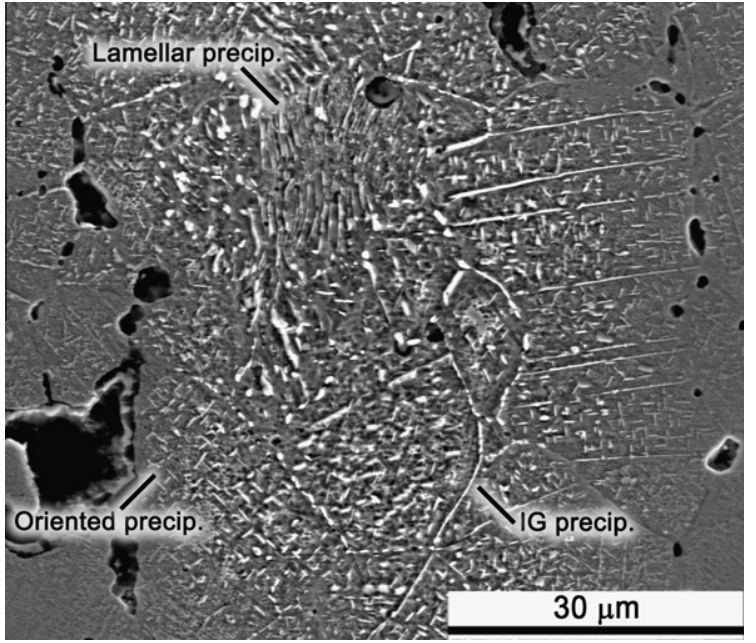

Fig. 8. SEM micrograph of $25 \mathrm{~N}$ sensitized at $875^{\circ} \mathrm{C}$ for $48 \mathrm{~h}$.

[28]. For $1.5 \mathrm{~h}$, the sensitization at $875^{\circ} \mathrm{C}$ was slower than at $675^{\circ} \mathrm{C}$ but became more aggressive for longer sensitization times. The sensitization behaviour of ferritic SS sintered in vacuum was found to be different from samples sintered in nitrogen and was dependent on temperature. At $675^{\circ} \mathrm{C}$, the maximum sensitization was detected for the shortest treatment and a progressive repassivation effect with sensitization time was observed. However, at $875^{\circ} \mathrm{C}$, a constant increase in the DOS parameters was registered and only after $48 \mathrm{~h}$ was repassivated. Compared with samples sintered in nitrogen, vacuum samples showed even more DOS. The effect of sensitization for duplex SS sintered in vacuum was similar at both temperatures. A progressive increase of reactivation parameters was observed with the time. The repassivation effect, found on samples sintered in nitrogen, was not detected. At $675^{\circ} \mathrm{C}$, the reactivation parameters were lower but the etching mechanism was similar to the samples sintered in nitrogen. First, the dissolution of the transformed mixed constituent occurred, then IG in austenite and finally, for the longest treatment, TG in austenite. The kinetics at $875^{\circ} \mathrm{C}$ were similar but the reactivation values were double than at $675^{\circ} \mathrm{C}$. The microstructure observed before testing confirmed the more intense sensitization for higher temperature. Regarding the effect of the sintering atmosphere it could be concluded that vacuum samples showed slower sensitization but for longer times the differences became less noticeable, Fig. 15.

\subsection{Double Loop Electrochemical Potentio-Kinetic Reactivation Test (DLEPR)}

DLEPR shows the advantage of being independent of surface finish and the results are no so sensitive to test conditions and specimens morphology, including the influence of porosity. In a previous work [14] the authors investigated the IGC of some PM duplex SS sintered in nitrogen in the as-sintered and solution annealed states. The results showed good agreement with those obtained with other electrochemical techniques. The reactivation and passivation peaks were shifted to nobler potentials when the amount of austenite powder increased. As expected, 316L N showed the best results and again for duplex SS the DOS parameters decreased when the austenite/ferrite ratio increased. The ferritic SS clearly showed the worst corrosion behaviour. For annealed materials, specimens sintered in nitrogen showed a strong reduction of sensitization that was not the case for samples sintered in vacuum. Therefore, after annealing, samples sintered in both atmospheres presented similar corrosion behaviour.
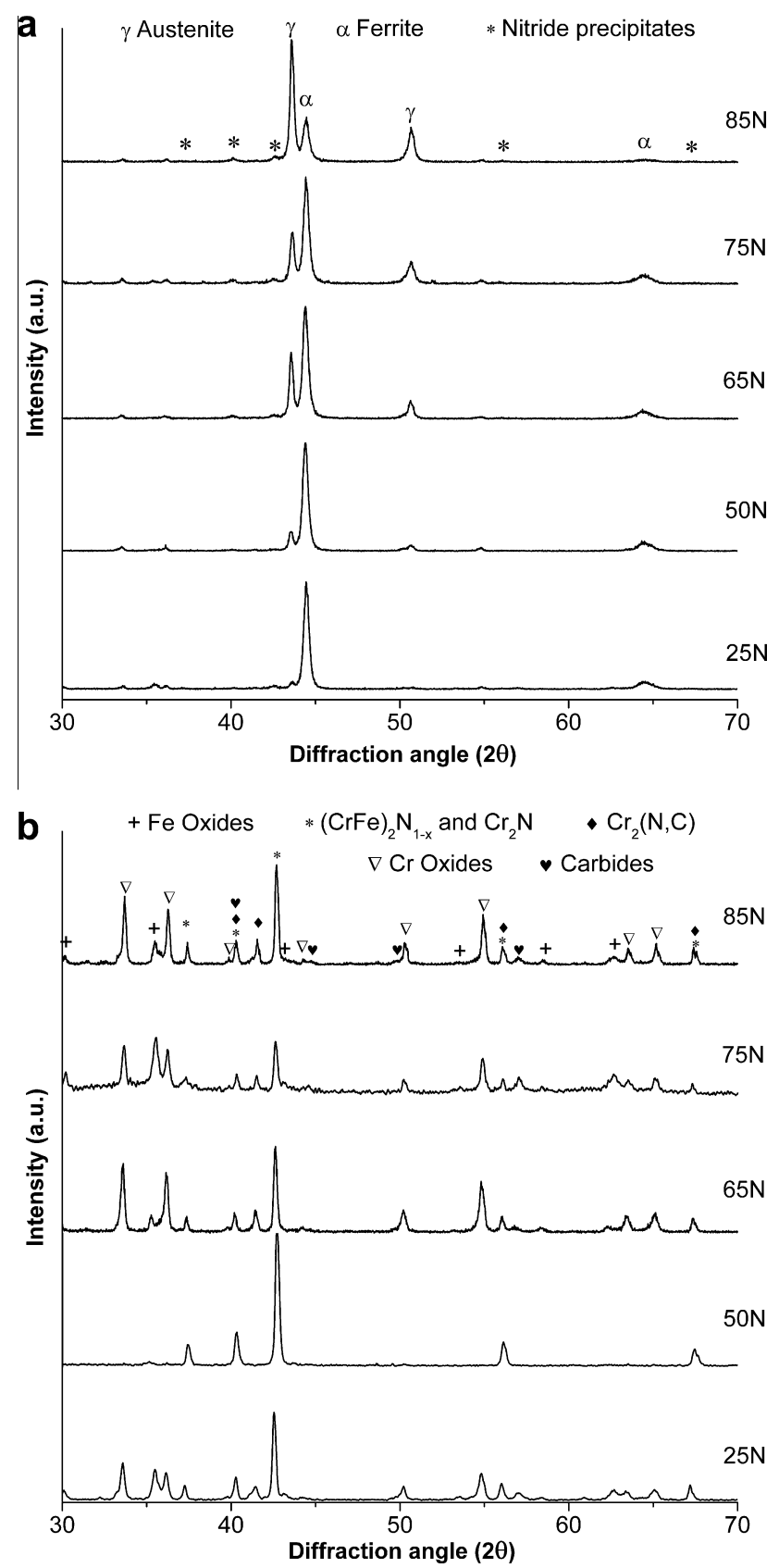

Fig. 9. X-ray diffractograms of bulk extracted $25 \mathrm{~N}, 50 \mathrm{~N}, 65 \mathrm{~N}, 75 \mathrm{~N}$ and $85 \mathrm{~N}$.

The DLEPR results for samples sensitized at 675 and $875{ }^{\circ} \mathrm{C}$ are in good agreement with those found by the EPR test. Table 6 shows the DOS parameters for some duplex specimens sintered in nitrogen and submitted to four ageing times (1.5, 4, 8 and $48 \mathrm{~h}$ ).

For sensitization at $675{ }^{\circ} \mathrm{C}$, once again, the worst behaviour corresponded to the sample richer in ferritic powder and this was mainly associated to dissolution of the lamellar constituent. The fact that DLEPR test can also dissolve part of the ferrite [5] must be considered. Regarding the influence of treatment time, for $1.5 \mathrm{~h}$, the DOS parameters were already high and the repassivation effect was observed after $4 \mathrm{~h}$. The $85 \mathrm{~N}$ sample showed the best behaviour where a progressive increase of charge and current density ratios with the sensitization time was observed. This was in accordance with the EPR method and with the observation of the surface after the test that showed mainly grain boundary dissolution. 

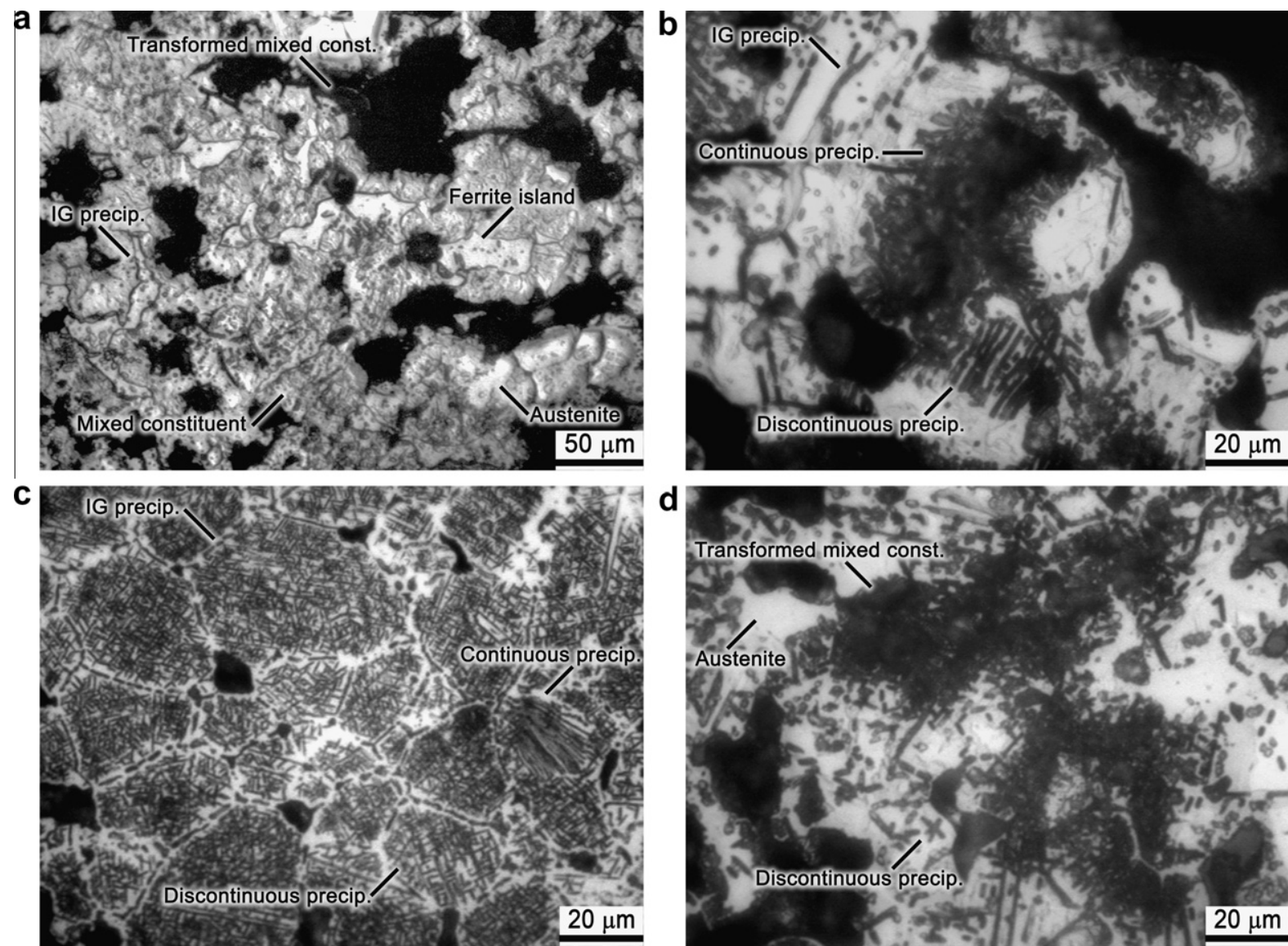

Fig. 10. Microstructures after Practice A (ASTM A262) of 50V sensitized at $875{ }^{\circ} \mathrm{C}$ for (a) 1.5 , (b) 4 , (c) 8 and (d) $48 \mathrm{~h}$.

Table 3

EPR results for samples sintered in nitrogen and sensitized at $675^{\circ} \mathrm{C}$.

\begin{tabular}{|c|c|c|c|c|}
\hline Samples & $\begin{array}{l}\text { Sensitization time } \\
\text { (h) }\end{array}$ & $\begin{array}{l}E_{\text {corr }} \\
\left(\mathrm{mV}_{\mathrm{SCE}}\right)\end{array}$ & $\begin{array}{l}Q_{r}^{a} \\
\left(10^{4} \mathrm{C} / \mathrm{m}^{2}\right)\end{array}$ & $\begin{array}{l}I_{\mathrm{r}}^{\mathrm{b}} \\
\left(\mathrm{A} / \mathrm{m}^{2}\right)\end{array}$ \\
\hline \multirow[t]{4}{*}{$25 N$} & $1 \frac{1}{2}$ & -469 & 16.3 & 1420 \\
\hline & 4 & -478 & 15.3 & 1410 \\
\hline & 8 & -485 & 13.3 & 1290 \\
\hline & 48 & -479 & 18 & 1690 \\
\hline \multirow[t]{4}{*}{$50 \mathrm{~N}$} & $1 \frac{1}{2}$ & -462 & 10.6 & 883 \\
\hline & 4 & -448 & 3.5 & 313 \\
\hline & 8 & -465 & 8.1 & 900 \\
\hline & 48 & -445 & 11.6 & 901 \\
\hline \multirow[t]{4}{*}{$65 N$} & $1 \frac{1}{2}$ & -437 & 8.1 & 727 \\
\hline & 4 & -433 & 4.7 & 399 \\
\hline & 8 & -448 & 6.3 & 505 \\
\hline & 48 & -462 & 8.3 & 597 \\
\hline \multirow[t]{4}{*}{$75 N$} & $1 \frac{1}{2}$ & -421 & 3.9 & 291 \\
\hline & 4 & -393 & 4.1 & 318 \\
\hline & 8 & -406 & 7.7 & 587 \\
\hline & 48 & -409 & 12.8 & 1010 \\
\hline \multirow[t]{4}{*}{$85 N$} & $1 \frac{1}{2}$ & -386 & 1.6 & 160 \\
\hline & 4 & -395 & 3.8 & 314 \\
\hline & 8 & -419 & 4.1 & 314 \\
\hline & 48 & -395 & 6.6 & 685 \\
\hline \multirow[t]{4}{*}{$316 \mathrm{~L} \mathrm{~N}$} & $1 \frac{1}{2}$ & -307 & 1.5 & 153 \\
\hline & 4 & -312 & 2.6 & 287 \\
\hline & 8 & -350 & 3.6 & 445 \\
\hline & 48 & -346 & 11.3 & 1450 \\
\hline \multirow[t]{4}{*}{ 430L N } & $1 \frac{1}{2}$ & -546 & 22.9 & 1850 \\
\hline & 4 & -547 & 21.6 & 1970 \\
\hline & 8 & -550 & 32.7 & 2310 \\
\hline & 48 & -532 & 36 & 2990 \\
\hline
\end{tabular}

a Reactivation charge.

b Reactivation current density.
Table 4

EPR results for samples sintered in nitrogen and sensitized at $875{ }^{\circ} \mathrm{C}$

\begin{tabular}{|c|c|c|c|c|}
\hline Samples & $\begin{array}{l}\text { Sensitization time } \\
\text { (h) }\end{array}$ & $\begin{array}{l}E_{\text {corr }} \\
\left(\mathrm{mV}_{\mathrm{SCE}}\right)\end{array}$ & $\begin{array}{l}Q_{r}^{\mathrm{a}} \\
\left(10^{4} \mathrm{C} / \mathrm{m}^{2}\right)\end{array}$ & $\begin{array}{l}I_{\mathrm{r}}^{\mathrm{b}} \\
\left(\mathrm{A} / \mathrm{m}^{2}\right)\end{array}$ \\
\hline \multirow[t]{4}{*}{$25 N$} & $1 \frac{11 / 2}{2}$ & -471 & 58.6 & 3510 \\
\hline & 4 & -489 & 17.2 & 1250 \\
\hline & 8 & -492 & 20.1 & 1500 \\
\hline & 48 & -496 & 20.5 & 1540 \\
\hline \multirow[t]{4}{*}{$50 \mathrm{~N}$} & $11 / 2$ & -468 & 14.1 & 1030 \\
\hline & 4 & -459 & 13.3 & 1010 \\
\hline & 8 & -462 & 17.1 & 1280 \\
\hline & 48 & -432 & 16.1 & 1250 \\
\hline \multirow[t]{4}{*}{$65 N$} & $1 \frac{1}{2}$ & -457 & 11.3 & 845 \\
\hline & 4 & -434 & 6.8 & 524 \\
\hline & 8 & -434 & 10.6 & 422 \\
\hline & 48 & -415 & 12.3 & 1220 \\
\hline \multirow[t]{4}{*}{$75 N$} & $11 / 2$ & -435 & 11.3 & 871 \\
\hline & 4 & -435 & 6.7 & 580 \\
\hline & 8 & -417 & 7.8 & 725 \\
\hline & 48 & -414 & 13.2 & 1320 \\
\hline \multirow[t]{4}{*}{$85 N$} & $11 / 2$ & -403 & 9.5 & 950 \\
\hline & 4 & -397 & 2.5 & 404.0 \\
\hline & 8 & -404 & 4.0 & 539 \\
\hline & 48 & -328 & 8.8 & 1030 \\
\hline \multirow[t]{4}{*}{$316 \mathrm{~L} \mathrm{~N}$} & $11 / 2$ & -325 & 6.1 & 780 \\
\hline & 4 & -310 & 5.1 & 577 \\
\hline & 8 & -394 & 6.5 & 1090 \\
\hline & 48 & -358 & 13.8 & 1530 \\
\hline \multirow[t]{4}{*}{ 430L N } & $11 / 2$ & -533 & 23.3 & 1570 \\
\hline & 4 & -532 & 26.4 & 1910 \\
\hline & 8 & -524 & 32.7 & 2890 \\
\hline & 48 & -533 & 42.5 & 3930 \\
\hline
\end{tabular}

a Reactivation charge.

b Reactivation current density. 


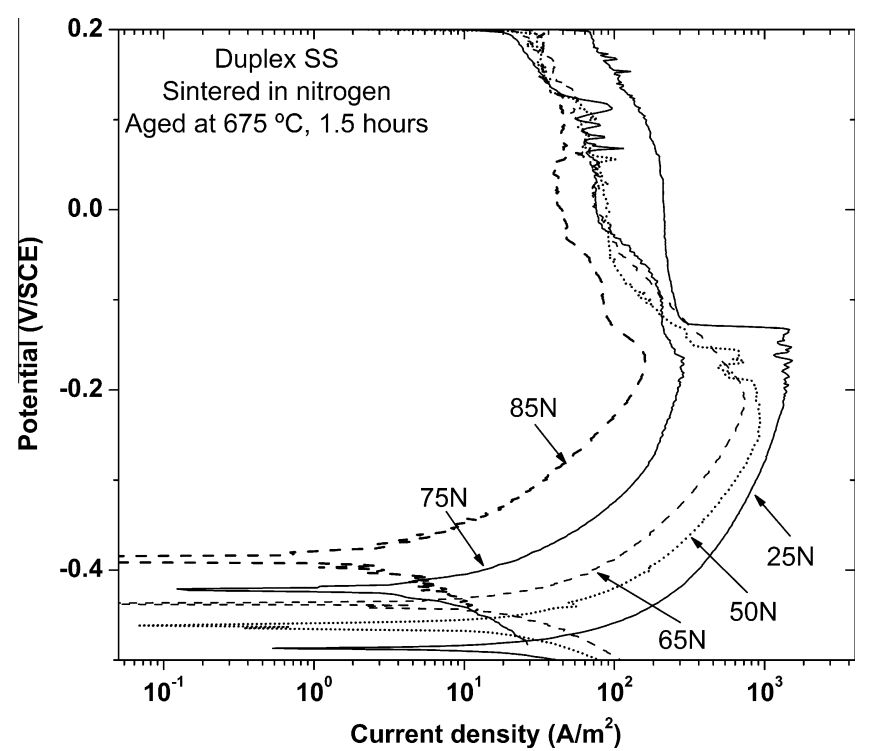

Fig. 11. Curves of EPR for duplex SS sintered in nitrogen and sensitized at $675^{\circ} \mathrm{C}$ for $1.5 \mathrm{~h}$.

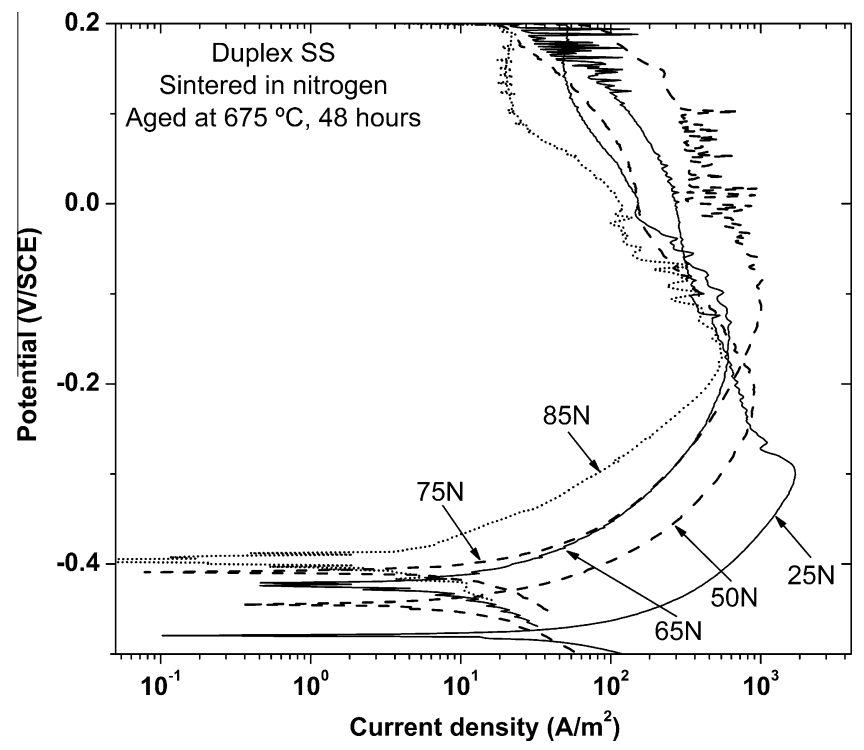

Fig. 12. Curves of EPR for duplex SS sintered in nitrogen and sensitized at $675^{\circ} \mathrm{C}$ for $48 \mathrm{~h}$.

The DLEPR results indicated that the selective corrosion kinetics of samples aged at $875^{\circ} \mathrm{C}$ were different. For all duplex mixtures, ageing at $875^{\circ} \mathrm{C}$ promoted higher $Q_{\mathrm{r}} / Q_{\mathrm{a}}$ and $I_{\mathrm{r}} / I_{\mathrm{a}}$ ratios than ageing at $675{ }^{\circ} \mathrm{C}$ for the shortest heat treatment. For longer ageing times, it became beneficial due to re-diffusion of chromium into depleted areas. For $48 \mathrm{~h}$, a new increase of parameters was registered. This tendency, which was not observed in specimens aged at $675^{\circ} \mathrm{C}$, was especially registered by the charge ratio.

For the aged specimens sintered in vacuum there is good correlation with EPR test, in spite of the negative effect of ageing heat treatments, the ratios obtained were lower than those registered for samples sintered in nitrogen, Table 6 . The same effect of sensitization time was observed at both temperatures. The values (especially current density ratio) increased with the time and repassivation was not observed. Ageing at $875{ }^{\circ} \mathrm{C}$ was also critical, particularly for sensitization times above $4 \mathrm{~h}$ when a complete dissolution of transformed mixed constituent was observed.

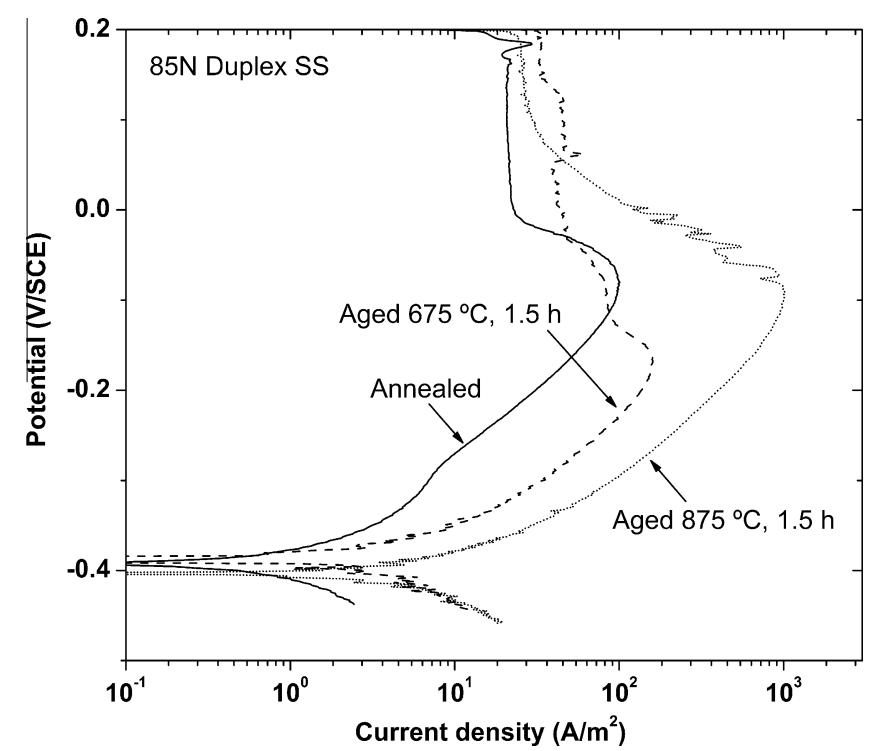

Fig. 13. Curves of EPR for $85 \mathrm{~N}$, annealed and sensitized at 675 and $875^{\circ} \mathrm{C}$ for $1.5 \mathrm{~h}$.

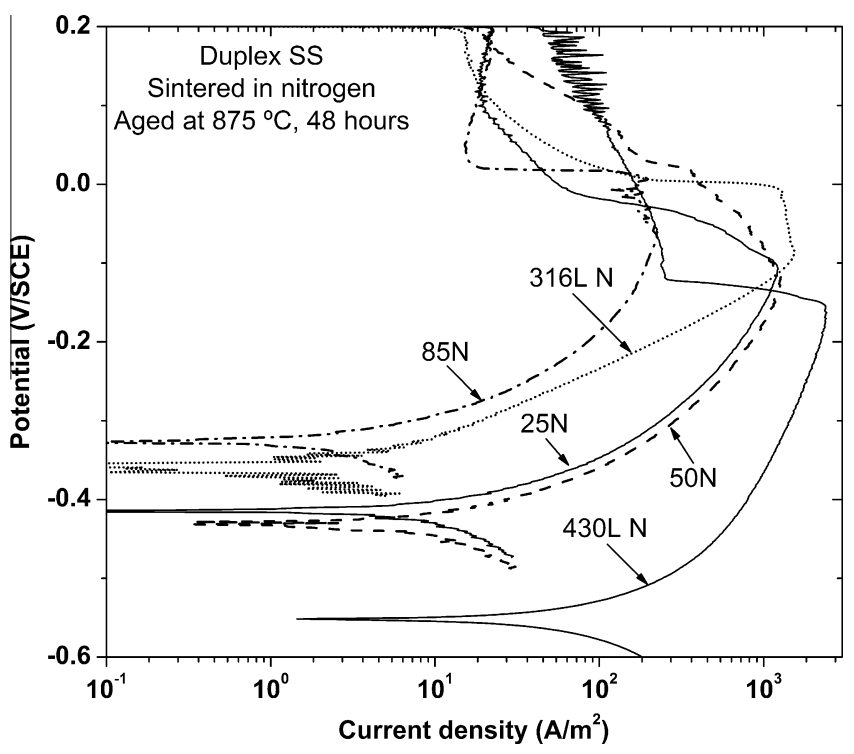

Fig. 14. Curves of EPR for duplex SS sintered in nitrogen and sensitized at $875^{\circ} \mathrm{C}$ for $48 \mathrm{~h}$.

Similar conclusions can be obtained from both reactivation methods but with some differences. It can be said that the sensitivity of EPR is greater at low sensitization levels, by the contrary, for higher DOS, DLEPR is more than adequate since it shows higher saturation levels.

\section{Conclusions}

EPR and DLEPR can successfully detect the effect of ageing heat treatment on the DOS in PM duplex SS. The treatment induces a strong sensitization in comparison to solution annealed samples and shows corrosion behaviour progressively closer to that observed on as-sintered samples. The IGC susceptibility is a function of austenite/ferrite ratio, sintering atmosphere, and temperaturetime ageing conditions.

For all ageing conditions, the reactivation data of samples sintered in nitrogen decrease when the amount of austenite powder 
Table 5

EPR results for samples sintered in vacuum, sensitized at 675 or $875{ }^{\circ} \mathrm{C}$ for $1 \frac{1}{2}, 4,8$ and $48 \mathrm{~h}$.

\begin{tabular}{|c|c|c|c|c|c|}
\hline Samples & $\begin{array}{l}\text { Sensitization temperature } \\
\left({ }^{\circ} \mathrm{C}\right)\end{array}$ & $\begin{array}{l}\text { Sensitization time } \\
\text { (h) }\end{array}$ & $\begin{array}{l}E_{\text {corr }} \\
\left(\mathrm{mV}_{\mathrm{SCE}}\right)\end{array}$ & $\begin{array}{l}Q_{r}^{\mathrm{a}} \\
\left(10^{4} \mathrm{C} / \mathrm{m}^{2}\right)\end{array}$ & $\begin{array}{l}I^{\mathrm{b}} \\
\left(\mathrm{A} / \mathrm{m}^{2}\right)\end{array}$ \\
\hline \multirow[t]{8}{*}{ 430L V } & 675 & $11 / 2$ & -545 & 28.4 & 2780 \\
\hline & & 4 & -536 & 20.6 & 2180 \\
\hline & & 8 & -548 & 16.3 & 1570 \\
\hline & & 48 & -547 & 13.1 & 1060 \\
\hline & 875 & $11 / 2$ & -532 & 37.2 & 3690 \\
\hline & & 4 & -533 & 27 & 2300 \\
\hline & & 8 & -532 & 33.2 & 3120 \\
\hline & & 48 & -527 & 25.2 & 2170 \\
\hline \multirow[t]{8}{*}{$316 \mathrm{~L} \mathrm{~V}$} & 675 & $1 \frac{1}{2}$ & -336 & 4.2 & 460 \\
\hline & & 4 & -318 & 4.6 & 489 \\
\hline & & 8 & -335 & 3.9 & 482 \\
\hline & & 48 & - & - & - \\
\hline & 875 & $11 / 2$ & -322 & 2.9 & 383 \\
\hline & & 4 & -340 & 7.1 & 937 \\
\hline & & 8 & -361 & 4.9 & 698 \\
\hline & & 48 & - & - & - \\
\hline \multirow[t]{8}{*}{$50 \mathrm{~L} \mathrm{~V}$} & 675 & $11 / 2$ & -415 & 3.6 & 368 \\
\hline & & 4 & -423 & 4.2 & 382 \\
\hline & & 8 & -433 & 6.2 & 572 \\
\hline & & 48 & -421 & 7.1 & 676 \\
\hline & 875 & $11 / 2$ & -430 & 6.4 & 520 \\
\hline & & 4 & -421 & 8.3 & 830 \\
\hline & & 8 & -425 & 13.5 & 1020 \\
\hline & & 48 & -397 & 14 & 825 \\
\hline
\end{tabular}

a Reactivation charge.

b Reactivation current density.

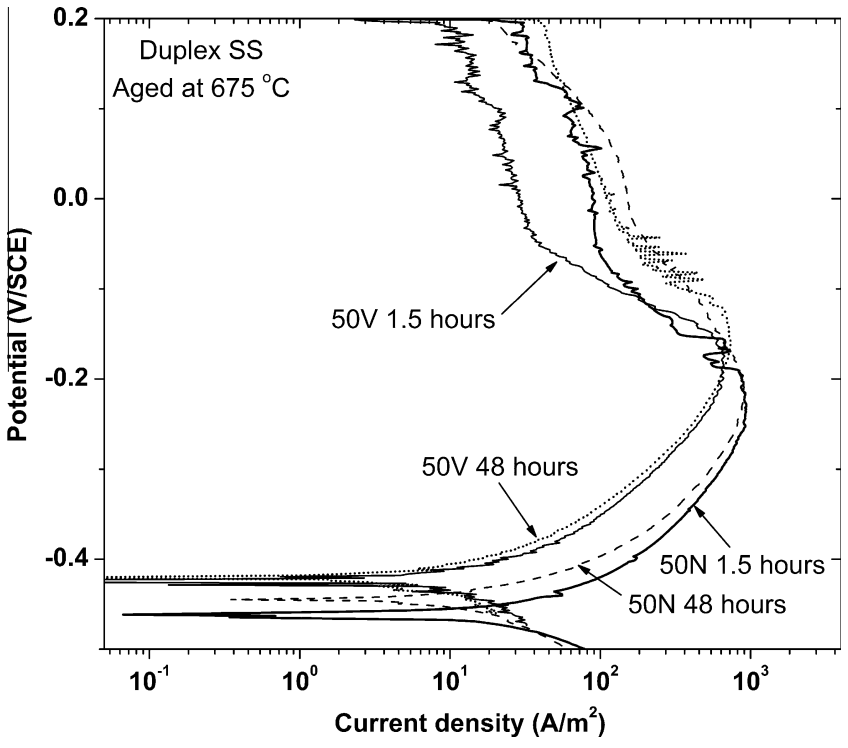

Fig. 15. Curves of EPR for $50 \mathrm{~V}$ and $50 \mathrm{~N}$, sensitized at $675^{\circ} \mathrm{C}$ for 1.5 and $48 \mathrm{~h}$.

increases.. For both ageing temperatures $\left(675\right.$ and $\left.875^{\circ} \mathrm{C}\right)$, the $25 \mathrm{~N}$, $50 \mathrm{~N}, 65 \mathrm{~N}$, and $75 \mathrm{~N}$ samples show a similar evolution with sensitization time while $85 \mathrm{~N}$ differs and shows behaviour similar to austenitic base material.

Fast sensitization is detected for both ageing temperatures associated with dissolution of the mixed constituent. Furthermore, the chromium depleted areas of the transformed mixed constituent showed a rapid repassivation effect. The longest ageing time gives an additional increase of DOS parameters associated with transgranular chromium-depleted austenite. Two precipitation mechanisms are observed: cellular and discontinuous precipitation. These are the main factors contributing to IGC behaviour.
Table 6

DLEPR results for samples sintered in nitrogen and in vacuum and sensitized at 675 or $875^{\circ} \mathrm{C}$ for $1 \frac{1}{2}, 4,8$ and $48 \mathrm{~h}$.

\begin{tabular}{|c|c|c|c|}
\hline Samples & $\begin{array}{l}\text { Sensitization time } \\
\text { (h) }\end{array}$ & $Q_{r} / Q_{a}{ }^{a}$ & $I_{\mathrm{r}} / I_{\mathrm{a}}^{\mathrm{b}}$ \\
\hline \multicolumn{4}{|c|}{ Panel (a) sensitized at $675^{\circ} \mathrm{C}$} \\
\hline \multirow[t]{4}{*}{$50 \mathrm{~N}$} & $11 / 2$ & 92.4 & 87.0 \\
\hline & 4 & 79.3 & 71.0 \\
\hline & 8 & 82.4 & 81.7 \\
\hline & 48 & 100.5 & 78.6 \\
\hline \multirow[t]{4}{*}{$65 N$} & $11 / 2$ & 54.6 & 44.8 \\
\hline & 4 & 64.7 & 51.7 \\
\hline & 8 & 74.3 & 60.9 \\
\hline & 48 & 88 & 79.3 \\
\hline \multirow[t]{4}{*}{$85 N$} & $11 / 2$ & 40.5 & 42 \\
\hline & 4 & 66 & 55 \\
\hline & 8 & 70.7 & 68.8 \\
\hline & 48 & 85.8 & 70.5 \\
\hline \multirow[t]{4}{*}{$50 \mathrm{~V}$} & $11 / 2$ & 40.7 & 34.2 \\
\hline & 4 & 48.9 & 39.2 \\
\hline & 8 & 51.5 & 40.7 \\
\hline & 48 & 56.2 & 42.5 \\
\hline \multicolumn{4}{|c|}{ Panel (b) sensitized at $875^{\circ} \mathrm{C}$} \\
\hline \multirow[t]{4}{*}{$50 \mathrm{~N}$} & $11 / 2$ & 96.5 & 96.7 \\
\hline & 4 & 91.8 & 96.3 \\
\hline & 8 & 70.3 & 70.1 \\
\hline & 48 & 89.8 & 75.7 \\
\hline \multirow[t]{4}{*}{$65 N$} & $11 / 2$ & 86.5 & 79.1 \\
\hline & 4 & 65.6 & 57.4 \\
\hline & 8 & 61.9 & 51.1 \\
\hline & 48 & 76.6 & 70.2 \\
\hline \multirow[t]{4}{*}{$85 N$} & $11 / 2$ & 79.1 & 75 \\
\hline & 4 & 66.2 & 59.8 \\
\hline & 8 & 51.5 & 46.8 \\
\hline & 48 & 75.4 & 57.4 \\
\hline \multirow[t]{4}{*}{$50 \mathrm{~V}$} & $11 / 2$ & 50.2 & 48.7 \\
\hline & 4 & 65.4 & 56.6 \\
\hline & 8 & 61.9 & 56.1 \\
\hline & 48 & 65.2 & 74.2 \\
\hline
\end{tabular}

a Reactivation/passivation charges ratio.

b Reactivation/passivation current densities ratio. 
For ageing at $875^{\circ} \mathrm{C}$ the sensitization for duplex SS sintered in nitrogen is even faster than at $675^{\circ} \mathrm{C}$. The DOS parameters decrease when austenite/ferrite ratio increases. The corrosion resistance of $85 \mathrm{~N}$ duplex SS for longer ageing heat treatment is even better than austenitic SS.

Duplex stainless steels sintered in vacuum also show high IGC susceptibility although there are no nitrogen precipitates. For shorter ageing, they show slower sensitization than samples sintered in nitrogen but, for longer times, the differences become less noticeable. The dissolution of the mixed constituent and the TG chromium-carbide precipitation in austenite are the main factors for short and long ageing treatment respectively. Ageing at $875^{\circ} \mathrm{C}$ is more critical than ageing at $675^{\circ} \mathrm{C}$.

The sensitivity of EPR is greater at low DOS. On the contrary, for higher DOS, DLEPR is more adequate since it shows higher saturation levels. The charge is a more adequate parameter than current density to detect the influence of ageing on the IGC for PM SS.

\section{Acknowledgement}

Financial support from Ministerio de Ciencia e Innovación, Dirección General de Programas y Transferencia de Conocimiento, Proyectos I+D, reference MAT2008-02788, is gratefully acknowledged.

\section{References}

[1] P. Datta, G.S. Upadhyaya, Copper enhances the sintering of duplex PM stainless steels, Met. Powder Rep. 1 (1999) 26-29.

[2] P. Datta, G.S. Upadhyaya, Sintered duplex stainless steel from premixes of 316L and 434L powders, Mater. Chem. Phys. 67 (2001) 234-242.

[3] A. Pardo, E. Otero, J. Hernaez, Influence of microstructure on the intergranular corrosion resistance of $24.4 \mathrm{Cr} / 7.4 \mathrm{Ni}$ duplex stainless steel, Mater. Charact. 26 (1991) 149-153.

[4] K. Ravindarnath, S.N. Malhotra, The influence of aging on the intergranular corrosion of 22 crhromium-5 niquel duplex stainless steel, Corros. Sci. 37 (1995) 121-132.

[5] N. Lopez, M. Cid, M. Puiggali, I. Azkarate, A. Pelayo, Application of double loop electrochemical potentiodynamic reactivation test to austenitic and duplex stainless steels, Mater. Sci. Eng. A 229 (1997) 123-128.

[6] V.S. Moura, L.D. Lima, J.M. Pardal, .Y. Kina, R.R.A. Corte, S.S.M. Tavares, Influence of microstructure on the corrosion resistance of the duplex stainless steel UNS S31803, Mater. Charact. 59 (2008) 1127-1132.

[7] I.N. Bastos, S.S.M. Tavares, F. Dalard, R.P. Nogueira, Effect of microstructure on corrosion behavior of superduplex stainless steel at critical environment conditions, Scr. Mater. 57 (2007) 913-916.

[8] J.M. Pardal, S.S.M. Tavares, M.C. Fonseca, J.A. de Souza, R.R.A. Corte, H.F.G. de Abreu, Influence of the grain size on deleterious phase precipitation in superduplex stainless steel UNS S32750, Mater. Charact. 60 (2009) 165-172.

[9] R. Chaves, I. Costa, H.G. de Melo, S. Wolynec, Evaluation of selective corrosion in UNS S31803 duplex stainless steel with electrochemical impedance spectroscopy, Electrochim. Acta 51 (2006) 1842-1846.

[10] F.A. Corpas Iglesias, J.M. Ruiz Roman, J.M. Ruiz Prieto, L. Garcia Cambronero, F.J. Iglesias Godino, Effect of nitrogen on sintered duplex stainless steels, Powder Metall. 46 (2003) 39-42.

[11] L.A. Dobrzanski, Z. Brytan, M. Actis Grande, M. Rosso, Corrosion resistance of sintered duplex stainless steels in salt spray test, J. Mater. Process. Technol. 192-193 (2007) 443-448.

[12] J.M. Torralba, A. Monsoriu, J.M. Ruiz-Roman, J.R. Ibars, F. Velasco, Corrosion behaviour of $\mathrm{P} / \mathrm{M}$ duplex stainless steels made from prealloyed and mixed powders, J. Mater. Process. Technol. 53 (1995) 433-440.

[13] L.A. Dobrzanski, Z. Brytan, M. Actis Grande, M. Rosso, Corrosion behaviour of vacuum sintered duplex stainless steels, J. Mater. Process. Technol. 191 (2007) 161-164.

[14] C. García, F. Martín, Y. Blanco, M.P. de Tiedra, M.L. Aparicio, Corrosion behaviour of duplex stainless steels sintered in nitrogen, Corros. Sci. 51 (2009) 76-86.
[15] J. Kazior, M. Nykiel, T. Piexzonka, T. Markus Puscas, A. Molinari, Activated sintering of $\mathrm{P} / \mathrm{M}$ duplex stainless steel powders, J. Mater. Process. Technol. 157-158 (2004) 712-717.

[16] T. Marcu Puscas, A. Molinari, J. Kazior, T. Pieczonka, M. Nykiel, Sintering transformations in mixtures of austenitic and ferritic stainless steel powders, Powder Metall. 44 (2001) 48-52.

[17] D. Ornato, High density sintering of duplex stainless steels, Powder Metall. 45 (2002) 290-293.

[18] L.A. Dobrzanski, Z. Brytan, M.A. Grande, M. Rosso, E.J. Pallavicini, Properties of vacuum sintered duplex stainless steel, J. Mater. Process. Technol. 162-163 (2005) 286-292.

[19] H. Hannimen, J. Romu, R. Ilola, J. Tervo, A. Laitinen, Effects of processing and manufacturing of high nitrogen-containing stainless steels on their mechanical, corrosion and wear properties, J. Mater. Process. Technol. 117 (2001) 424-430.

[20] Chi-Shang Huang, Chia-Chang Shih, Effects of nitrogen and high temperature aging on $\sigma$ phase precipitation of duplex stainless steel, Mater. Sci. Eng. A 402 (2005) 66-75.

[21] E. Angelini, B. De Benedetti, F. Rosalbino, Microstructural evolution and localized corrosion resistance of an aged superduplex stainless steel, Corros. Sci. 46 (2004) 1351-1367.

[22] G. Lothongkum, P. Wongpanya, S. Morito, T. Furuhara, T. Maki, Effect of nitrogen on corrosion behaviour of $28 \mathrm{Cr}-7 \mathrm{Ni}$ duplex and microduplex stainless steels in air-saturated $3.5 \%$ wt\% $\mathrm{NaCl}$ solution, Corros. Sci. 48 (2006) 137-153.

[23] A. Igual Muñoz, J. García Antón, S. Lópex Nuévalos, J.L. Guiñón, V. Pérez Herranz, Corrosion studies of austenitic and duplex stainless steels in aqueous lithium bromide solution at different temperatures, Corros. Sci. 46 (2004) 2955-2974.

[24] Z. Cvijovic, G. Radenkovic, Microstructure and pitting corrosion resistance of annealed duplex stainless steel, Corros. Sci. 48 (2006) 2887-3906.

[25] Horng-Yih Liou, Rong-Iuan Hsieh, Wen-Ta Tsai, Microstructure and pitting corrosion in simulated heat affected zones of duplex stainless steels, Mater. Chem. Phys. 74 (2002) 33-42.

[26] V.S. Moura, L.D. Lima, J.M. Pardal, A.Y. Kina, R.R.A. Corte, S.S.M. Tavares, Influence of microstructure on the corrosion resistance of the duplex stainless steel UNS S31803, Mater. Charact. 59 (2008) 1127-1132.

[27] C. García, F. Martín, P. de Tiedra, L. García Cambronero, Pitting corrosion behaviour of PM austenitic stainless steels sintered in nitrogen-hydrogen atmosphere, Corros. Sci. 49 (2007) 1718-1736.

[28] C. García, F. Martín, P. de Tiedra, Y. Blanco, J.M. Ruíz-Roman, M. Aparicio, Electrochemical reactivation methods applied to PM austenitic stainless steels sintered in nitrogen-hydrogen atmosphere, Corros. Sci. 50 (2008) 687-697.

[29] F. Martín, C. García, P. de Tiedra, Y. Blanco, M.L. Aparicio, Sensitization of PM 430L stainless steel sintered in nitrogen-hydrogen atmosphere, Corrosion 64 (2008) 70-82.

[30] T. Otárola, S. Hollner, B. Bonnefois, M. Anglada, L. Coudreuse, A. Mateo, Embrittlement of a superduplex stainless steel in the range of $550-700{ }^{\circ} \mathrm{C}$, Eng. Fail. Anal. 12 (2005) 930-941.

[31] S.S.M. Tavares, V. Moura, V.C. da Costa, M.L.R. Ferreira, J.M. Pardal, Microstructural changes and corrosion resistance of AISI 310 S steel exposed to $600-800^{\circ} \mathrm{C}$, Mater. Charact. 60 (2009) 573-578.

[32] A. Weisbrodt-Reisch, M. Brummer, B. Hadler, B. Wolbank, E.A. Werner, Influence of temperature, cold deformation and a constant mechanical load on the microstructural stability of a nitrogen alloyed duple stainless steel, Mater. Sci. Eng. A 416 (2006) 1-10.

[33] C.J. Múñez, M.V. Utrilla, A. Ureña, Effect of temperature on sintered austenoferritic stainless steel microstructure, J. Alloy. Compd. 463 (2008) 552-558.

[34] ASTM Standard A262-91, Standard Practice for detecting susceptibility to intergranular attack on austenitic Stainless Steels, ASTM, Philadelphia, 1993, pp. 1-18.

[35] ASTM Standard G108-92, Standard test method for EPR for detecting sensitization of AISI Type 304 and 304L Stainless Steels, ASTM, Philadelphia, 1993, pp. 457-463.

[36] J. Ibars, Optimizacion de los metodos de polarizacion-reactivacion potenciocinetica para caracterizar el comportamiento de los aceros inoxidables austeniticos frente a la corrosion intergranular, Ph.D. Thesis, ETSII, Universidad Politécnica de Madrid, Madrid, 1987.

[37] W.L. Clarke, V.M. Romero, J.C. Danko, Detection of sensitization in stainless steels using electrochemical techniques, in: Proc. Corrosion/77, Reprint No. 180, NACE International, Houston, 1977.

[38] V. Cihal, R. Štefec, On the development of the electrochemical potentiokinetic method, Electrochim. Acta 46 (2001) 3867-3877.

[39] C. García, F. Martín, Y. Blanco, M.P. de Tiedra, M.L. Aparicio, Influence of sintering under nitrogen atmosphere on microstructures of powder metallurgy duplex stainless steels, Metall. Mater. Trans. A 40 (2009) 292-301. 